\title{
DC-link Control Filtering Options for Torque Ripple Reduction in Low Power Wind Turbines
}

\author{
Rafael Peña-Alzola, Member, IEEE, David Campos-Gaona, Member, IEEE, Peter Ksiazek, Member, IEEE, \\ and Martin Ordonez, Member, IEEE
}

\begin{abstract}
Small Wind Energy Conversion Systems (WECSs) are becoming an attractive option for distributed energy generation. WECSs use permanent magnet synchronous generators (PMSGs) directly coupled to the wind turbine and connected to the grid through a single-phase grid-tie converter. The loading produced on the DC-link is characterized by large ripple currents at twice the grid frequency. These ripple currents are reflected through the DC bus into the PMSG, causing increased heating and ripple torque. In this paper, the PMSG inverter is used to control the DC link voltage. In order to avoid reflecting the ripple currents into the PMSG, the feedback DC-link voltage is passed through a filter. The Butterworth filters, notch filters, antiresonant filter (ARF) and moving average filter (MAF) are considered. For a fair comparison, formulas are provided to tune the filter parameters so that DC-link voltage control will achieve the selected bandwidth. The different filtering options produce different levels of torque ripple reduction. Notch Filter, ARF and MAF obtain the best results and there is a trade-off between the filter implementation complexity, bandwidth, overshoot and the torque ripple reduction. Simulations and experiments using a 2.5 kW PMSG turbine generator validate the proposals.
\end{abstract}

Index Terms-Wind turbine, PMSG, torque ripple, load current, filters, Butterworth filter, notch filter, antiresonant filter, moving average filter, lead-lag.

\section{INTRODUCTION}

$\mathbf{S}$ MALL-SCALE wind turbines (of approximately $10 \mathrm{~kW}$ ) are becoming an attractive option for distributed generation [1]. Wind Energy Conversion Systems (WECSs) may be installed on even a modest-size property. WECSs mainly use Permanent Magnet Synchronous Generators (PMSGs) operating at variable frequency. The PMSG can be directly coupled to the wind turbine (no gearbox), reducing maintenance costs. The PMSG and its power inverter are used either to charge a large battery bank, or connected directly to the grid through a grid-tie converter [2]. In the case of a large battery bank, the system can operate as a standalone [3]. In cases where the main grid reaches the location of the WECSs, direct connection to the grid reduces system costs by negating the requirement for large battery banks.

R. Peña-Alzola and M. Ordonez are with the Department of Electrical and Computer Engineering, the University of British Columbia. 2332 Main Mall, Vancouver BC V6T 1Z4 Canada (e-mail: rafaelpa@ece.ubc.ca; mordonez@ieee.org).

D. Campos Gaona was with the University of British Columbia and now is with the Department of Electronic and Electrical Engineering, University of Strathclyde. Glasgow G1 1XW United Kingdom (e-mail: davidcg@ieee.org)

P. Ksiazek was with the University of British Columbia and now is with Alpha Technologies Ltd. 7700 Riverfront Gate, Burnaby, BC V5J 5M4 Canada (e-mail: peter.ksiazek@ieee.org).

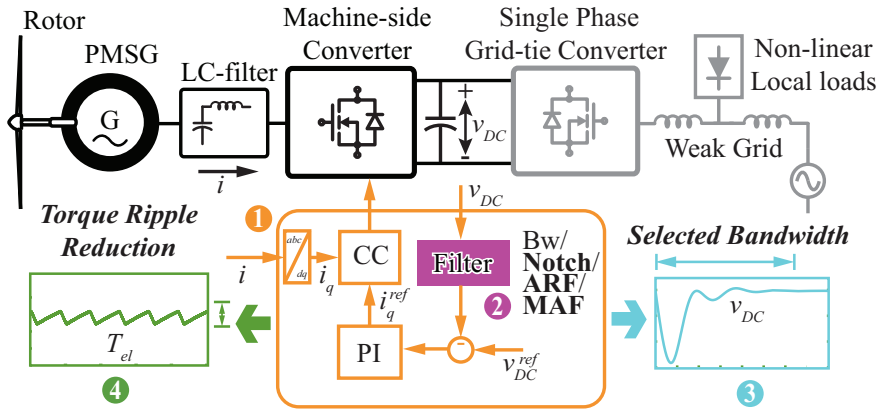

Fig. 1: Conceptual representation of the proposed control scheme for the small WECS. The machine-side inverter is used to control the DC link so as to increase stability (1). The feedback DC-link voltage is passed through the different filtering options (2). For a fair comparison between the different filtering options, formulas are provided to tune the filter parameters so that DC-link voltage control will achieve the selected bandwidth (3). The different filtering options produce different levels of torque ripple reduction (4). Notch Filter, $\mathrm{ARF}$ and MAF obtain the best results and there is a trade-off between the filter implementation complexity, bandwidth, overshoot and the torque ripple reduction.

The loading produced by the single-phase grid-tie converter on the DC bus is characterized by large input ripple currents at twice the grid frequency, present when using single-phase grid-tie converters. This situation is aggravated by the presence of weak grid, typical of remote areas, and local non-linear loads. These ripple currents are reflected through the DC bus into the PMSG, causing increased heating in the stator and ripple torque, which may lead to premature bearing failure and increased maintenance costs. The use of a passive diode rectifier and a boost converter connected to the PMSG is inexpensive but results in large current/torque ripple [4], [5]. The use of a full bridge three phase converter [2], [3], [6] allows sinusoidal current waveforms to be imposed on the PMSG with reduced torque ripple [4]. High power applications use NPC three level converters [7], and the use of Z-source converters has also been proposed [8]. The control of the DClink voltage is usually performed by the grid-tie converter [9], [10]. Using the machine-side converter to control the DC-link voltage has been proposed for high [11]-[13] and low power wind turbines [2].

In order to obtain grid/generator sinusoidal currents with single-phase converters, the DC-link voltage control should be prevented from canceling the pulsation of twice the grid frequency. To achieve this aim, the DC-link voltage feedback signal should be filtered to remove this component. The 


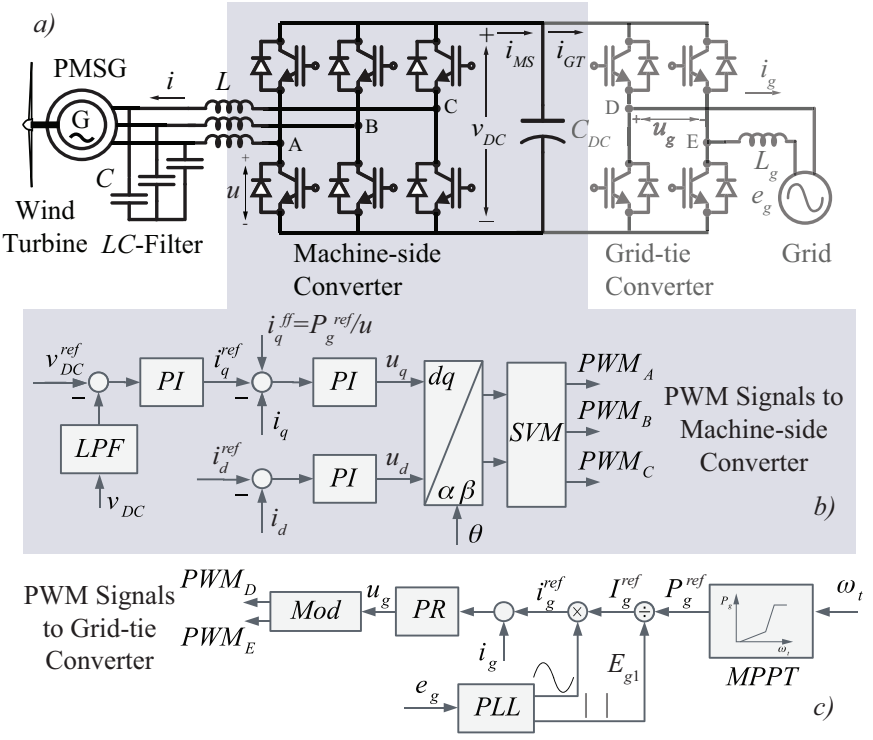

Fig. 2: a) Elements comprising the small WECS system and b) Block diagram of the overall control with the DC-link voltage controlled by the machine-side converter [11], [13], [26].

Butterworth filter has a frequency response that is as flat as possible in the passband [14], and is among the most common filters [15]-[17]. The notch filter makes null the spectral components around the notch frequency, and has been used recently for PLL grid synchronization [18] and $L C L$-filter resonance damping [19]. The antiresonant filter (ARF) [20] allows a notch filter to be implement using a FIR filter. The moving average filter has optimal filtering characteristics [14], and has been used recently for PLL grid synchronization [21], [22] and for DC-link voltage filtering [23]-[25].

In this paper, the stability limits of the DC-link voltage control by the machine-side and grid-converters are calculated. The machine-side converter (full bridge) is used to control the DC link to increase stability. In order to avoid reflecting the ripple currents into the PMSG, the feedback DC-link voltage is passed through a filter. The Butterworth filter (first and second order), notch filter, antiresonant filter (ARF) and moving average filter (MAF) are considered. The Padé approximant is used to select the proper filter parameters that will result in the same low frequency behavior. In order to obtain flexibility in selecting the proper bandwidth with the ARF and MAF, it is proposed that an auxiliary lead-lag filter be used. Parameter selection for all the filters is explained. Fig. 1 summarizes the proposals of the paper.

This paper is organized as follows. Section II describes the WECS and explains the overall control. Section III explains the different filtering options for the DC-link voltage control. Simulation results are shown in Section IV and experimental results with the $2.5 \mathrm{~kW}$ prototype in Sections V. Finally, Section VI concludes the paper.

\section{SYSTEM DESCRIPTION AND OVERALL CONTROL}

This section provides a short description of the WECS and its overall control.

\section{A. System description}

Fig. 2a represents the small WECS under study. It is comprised of a low power wind turbine, a PMSG, an $L C$-filter, the machine-side converter (three-phase full-bridge), the DClink capacitor, and finally, the grid-tie converter (single-phase full-bridge). The connection filter to the grid of the grid-tie converter is modeled as a simple inductor. The inductance $L_{g}$ includes the grid inductance, which may be large in weak grids of remote areas, and the leakage inductance of the isolating transformer. In order to reduce $\mathrm{dv} / \mathrm{dt}$, which can lead to the failure of the insulation, an additional $L C$-filter [27] is incorporated at the output of the machine-side converter. Fig. $2 b$ shows the block diagram of the overall control for the small-scale WECS system. Controlling the DC-link by using the machine-side converter was proposed in [11] for PMSGbased wind turbines connected to the grid. The PMSG-based wind turbine used in [11] was connected to the grid through a three-phase full bridge, instead of a single-phase converter as in Fig. 2a. In addition, there was an additional closed loop controller for the grid power in [11] that has been omitted in this paper. The main advantage of controlling the DC-link by using the machine-side converter is the increased capability for low voltage ride through (LVRT) [2], [28], [29]. During the short-time faults with reduced absorption capability of grid power, the machine-side converter will automatically store the energy surplus in the WECS inertia. More details on this control strategy can be found in [9], [13], [26], [30], [31].

\section{B. Symmetrical Optimum Criterion}

The symmetrical optimum (SO) criterion is used for tuning a PI controller when the plant consists of an integrator [16]. It is the standard procedure for the DC-link voltage control in gridtie converters [32], [33] and also for speed in servos [16]. The integrating plants correspond to the DC-link capacitance $C_{D C}$ and the motor inertia $J$, respectively. The SO criterion [34] is designed for optimal disturbance rejection and results in the highest phase margin. The proportional gain and integration time for the SO procedure are, respectively, given by:

$$
K_{p}=\frac{C_{D C}}{a K_{c l} \tau_{t d}} \quad \text { (1a) } \quad T_{i}=a^{2} \tau_{t d}
$$

with $a=2.4$ for closed loop damping $\eta=0.707$ or $a=3$ for triple closed loop pole with $\eta=1 ; K_{c l}$ is a gain relating the DC-link current and the inner control current and, finally, $\tau_{t d}=\tau_{c c}+\tau_{f f}$ the total delay due to the inner current control $\tau_{c c}$ and the feedback filter $\tau_{f f}$. These delays $\tau$ are the time constants of approximate first order systems. The procedure is illustrated in Fig. 3 for the DC-link voltage control performed by the machine-side converter explained later in this section. The achieved closed loop bandwidth is [32]:

$$
f_{b w S O}=\frac{1}{2 \pi a\left(\tau_{c c}+\tau_{f f}\right)}
$$

Based on the simulations done for this paper, using $a^{\frac{3}{2}}$ instead of $a$ in (2) results in a better approximation for the 


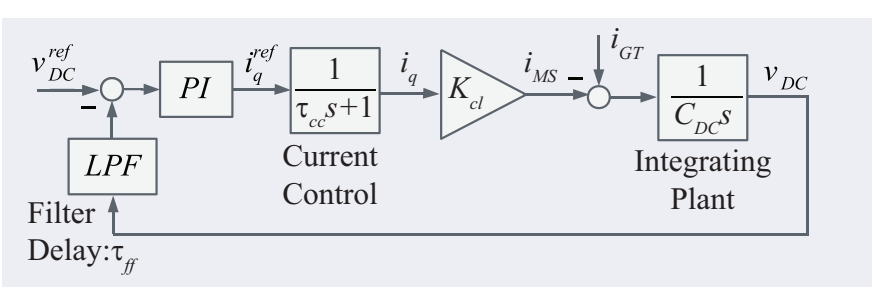

Fig. 3: Symmetrical optimum criterion for the DC-link voltage control performed by the machine-side converter.

traditional formula relating the bandwidth and the rise time $t_{r}=0.35 / f_{b w S O}$.

\section{Control of the DC-link voltage by the machine-side con- verter}

In Fig. 2b, vector control is used for the PMSG, with the reference frame aligned to the permanent magnet flux [16]. The direct current $i_{d}$ is set to zero to get the maximum torque per ampere in the stator [16]. The quadrature current $i_{q}$ is varied to keep the DC-link voltage $v_{D C}$ constant. The current loops use PI controllers for DC references, properly tuned according to the technical optimum [33].

The wind turbine has a large moment of inertia, which depends on the mass and on the squared distance, due to the blades. Because of the large total inertia of the wind turbine and the electrical machine PMSG, the mechanical time constant is much larger than the electrical time constants [31]. Therefore, the mechanical speed $\omega_{t}$ is considered constant for the following analysis. The power balance at the DC-link results as follows:

$$
\frac{1}{2} C_{D C} \frac{d v_{D C}^{2}}{d t}=P_{M S}-P_{G T}
$$

where $v_{D C}$ is the DC-link voltage, $P_{M S}$ the power flowing through the machine-side converter, and $P_{G T}$ the power flowing through the grid-tie converter. Neglecting all the losses in the machine-side converter and PMSG, it results as follows:

$$
P_{M S}=\frac{3}{2} \lambda p_{p} \omega_{t} i_{q}-\frac{3}{4} L\left(\frac{d i_{d}^{2}}{d t}+\frac{d i_{q}^{2}}{d t}\right)
$$

where $i_{d}$ and $i_{q}$ are the direct and quadrature currents respectively, $\lambda$ is the flux induced by the permanent magnets, $p_{p}$ is the number of pole pairs of the PMSG, $\omega_{t}$ the PMSG mechanical speed, and $L=L_{d}=L_{q}$ the $d$ - and $q$-axis inductances. The first term of (4) corresponds to the mechanical power and the second one to the energy variations in the inductances. The mechanical speed $\omega_{t}$ is approximately constant and so is the grid-tie converter power reference $P_{g}^{r e f}$ as they are related though a look-up table $P_{g}^{\text {ref }}=P_{g}^{\text {ref }}\left(\omega_{t}\right)$, see Fig. 2b. Neglecting losses, energy variations in the connection inductor and assuming a fast control of the grid current, $P_{G T}$ is approximately the grid power $P_{g} \approx P_{g}^{r e f} \approx P_{G T}$. In addition, $i_{d} \approx i_{d}^{r e f}=0$ and the following equation results:

$$
\frac{1}{2} C_{D C} \frac{d v_{D C}^{2}}{d t}=\frac{3}{2} \lambda p_{p} \omega_{t} i_{q}-\frac{3}{4} L \frac{d i_{q}^{2}}{d t}-P_{g}
$$

This equation is completely analogous to that of the threephase grid-tie converter with the PMSG internal voltage $\lambda p_{p} \omega_{t}$ acting as the grid voltage. Therefore, the very same smallsignal analysis as in [35] can be applied. The operation point is:

$$
\frac{3}{2} \lambda p_{p} \omega_{t} \bar{i}_{q}=P_{g}
$$

where the bar indicates the quiescent value. Taking into account that the constant power behaves like a negative resistance of value $R_{C P}=\bar{v}_{D C}^{2} / P_{g}$, the small-signal model of the DC-link voltage control results as follows:

$$
\frac{\tilde{v}_{D C}}{\tilde{i}_{q}}=-\frac{3}{4} \frac{R_{C P} \lambda p_{p} \omega_{t}}{\bar{v}_{D C}} \frac{-\frac{L \bar{i}_{q}}{\lambda p_{p} \omega_{t}} s+1}{-\frac{R_{C P} C_{D C}}{2} s+1}
$$

where the tilde indicates the variation around the quiescent value. Eq. (7) presents the non-minimum phase zero of the boost derived converters and a pole in the right side of the s-plane due to the constant power load.

In order to overcome the presence of the non-minimum phase zero, the bandwidth of the DC-link controllers should be slower than the zero:

$$
f_{b w S O}<<\frac{\lambda p_{p} \omega_{t}}{2 \pi L \bar{i}_{q}}
$$

Neglecting the non-minimum phase zero and the current loop response, the SO criterion is applied to the PI controller with the following value for $K_{c l}$ in (1),

$$
K_{c l}=\frac{3 \lambda p_{p} \omega_{t}}{2 \bar{v}_{D C}}
$$

The value $K_{c l}$ relates the quadrature current $i_{q}$ with the machine-side DC-link current $i_{M S}$, see Fig. 3. The proportional gain varies with the turbine speed, but variations in $\omega_{t}$ are very slow due to the large WECS inertia. In addition, $\omega_{t}$ has a minimum value determined by the cut-in speed. Under these conditions, gain scheduling can be safely used [36]. Considering the closed loop response and applying the Routh-Hurwitz criterion, the condition for stability is:

$$
P_{g}<\frac{f_{b w S O} C_{D C} \bar{v}_{D C}^{2} \pi}{a}
$$

Therefore, stability robustness increases for higher values of the DC-link control-bandwidth, capacitance and voltage. Under these circumstances, it is advisable to feed-forward the grid power $P_{g}$ [37], see Fig. 2b. Considering a small delay $\tau_{f f}$ in the feed-forward of $P_{g}$ so that $e^{\tau_{f f} s} \approx 1+\tau_{f f} s$, the small-signal average model results:

$$
\frac{\tilde{v}_{D C}}{\tilde{i}_{q}}=\frac{3}{2} \frac{R_{C P} \lambda p_{p} \omega_{t}}{\bar{v}_{D C}} \frac{-\frac{L \bar{i}_{q}}{\lambda p_{p} \omega_{t}} s+1}{C_{D C} s-\frac{2}{R_{C P}} \frac{\tau_{f f} s}{1+\tau_{f f} s}}
$$

for $\tau_{f f} \rightarrow 0$ the pole in the right side displaces toward the origin. Applying the Routh-Hurwitz criterion, the new condition for stability is: 


$$
P_{g}<\frac{C_{D C} \bar{v}_{D C}^{2}\left(4 \tau_{f f}^{2} f_{b w S O}^{2} \pi^{2}+2 \tau_{f f} a^{2} f_{b w S O} \pi+a^{3}\right)}{2 \tau_{f f} a\left(a^{2}+2 \tau_{f f} f_{b w S O} \pi\right)}
$$

It can be observed that the maximum power for stability increases for decreasing values of the feed-forward delay $\tau_{f f}$.

The DC-link voltage bandwidth achieved when using the SO criterion (2) can be excessively large if no feedback filter is included $\left(\tau_{t d}=\tau_{c c}\right)$. Considering the power through the single-phase grid-tie converter, the power balance of the DClink is:

$$
\begin{array}{r}
\frac{1}{2} C_{D C} \frac{d v_{D C}^{2}}{d t}=T_{e} \omega_{t}-P_{G S} \\
=\frac{3}{2} \lambda p_{p} i_{q} \omega_{t}-E_{g 1} I_{g}+E_{g 1} I_{g} \cos 2 \omega_{n}
\end{array}
$$

where $P_{G S}$ is the power though the single-phase grid-tie converter, $E_{g 1}$ the amplitude of the fundamental grid voltage, $I_{g}$ the amplitude of the grid current, and $\omega_{t}$ the grid frequency. If the bandwidth of the DC-link voltage control is selected to be higher than double the fundamental frequency $v_{D C} \approx v_{D C}^{r e f}$ and $d v_{D C}^{2} / d t \approx 0$. Substituting in (13), the following torque oscillation will be present:

$$
\tilde{T}_{e l} \omega_{t}=\frac{3}{2} \lambda p_{p} \tilde{i}_{q} \omega_{t} \approx-E_{g 1} I_{g} \cos 2 \omega_{n}
$$

If the pulsation of twice the grid frequency is canceled by selecting a large bandwidth, it is transmitted to the PSMG as damaging torque $\tilde{T}_{e l}$ and current ripple $\tilde{i}_{q}$. The advantage of using a full bridge, instead of a diode bridge and a boost converter, is lost. Hence, the DC-link voltage control should be selected to be less than double the fundamental frequency. For this purpose, the proportional gain of PI controller in (1) can be reduced. However, this reduces the phase margin and the SO criterion is no longer fulfilled. Therefore, it is more advisable to use the feedback filter that was considered in the SO tuning procedure.

\section{Control of the grid-side converter}

In Fig. 2c, the wind MPPT system consists in a simple look-up table $P_{g}^{r e f}=P_{g}^{r e f}\left(\omega_{t}\right)$ relating the rotor speed $\omega_{t}$ with the grid power reference $P_{g}^{r e f}$. This power corresponds to the maximum power supplied by the wind turbine for a given wind speed. A single-phase PLL provides the amplitude of the fundamental voltage $\sqrt{2} E_{g 1}$ and a unit-amplitude sinusoidal waveform in phase with the fundamental voltage. This allows the calculating of the sinusoidal current reference $i_{g}^{r e f}$, which has an amplitude $\sqrt{2} I_{g}^{\text {ref }}$ so that $P_{g}^{r e f}=E_{g 1} I_{g}^{r e f}$. The current loop uses a PR controller for the sinusoidal reference, which is tuned according to [38]. The resulting grid current $i_{g}$ is sinusoidal and in phase with fundamental voltage so that the power factor is unity. The torque equation for the wind turbine shaft is:

$$
T_{w}-T_{e}=J_{t} \frac{d \omega_{t}}{d t}
$$

where $T_{w}$ is the aerodynamic torque of the wind turbine, $T_{e}$ is the PMSG electrical torque, $J_{t}$ is the overall inertia and, $\omega_{t}$ is the wind turbine speed. Neglecting all losses, energy variations of the passive elements and fast transients, the electrical power produced by the PMSG is the power supplied to the grid $T_{e} \omega_{t} \approx P_{g} \approx P_{g}^{r e f}$. Therefore, the power balance results in:

$$
P_{w}-P_{g}^{r e f}=\frac{1}{2} J_{t} \frac{d \omega_{t}^{2}}{d t}
$$

Linearizing around the operation point, the variation of the wind turbine speed results as follows:

$$
\tilde{P}_{w}-k_{P_{g}} \tilde{\omega}_{t}=J_{t} \bar{\omega}_{t} \frac{d \tilde{\omega}_{t}}{d t}
$$

where

$$
k_{P_{g}}=\left.\frac{d P_{g}^{r e f}\left(\omega_{t}\right)}{d \omega_{t}}\right|_{\omega_{t}=\bar{\omega}_{t}}
$$

In order to consider the wind turbine speed approximately constant for the stability analysis, the time constant of (18) should be much higher than the bandwidth of the DC-link voltage control. Therefore, the total inertia must be sufficiently high to fulfill the following condition:

$$
\frac{J_{t} \bar{\omega}_{t}}{k_{P_{g}}}>>\frac{1}{2 \pi f_{b w S O}}
$$

As the wind turbine speed $\omega_{t}$ varies slowly, so the amplitude of the current reference does $I_{g}^{r e f}=P_{g}^{r e f}\left(\omega_{t}\right) / E_{g 1}$. With weak grids and non-linear loads nearby, the grid voltage presents the following harmonics:

$$
e_{g}=\sqrt{2} E_{g 1} \sin \left(\omega_{n} t\right)+\sum_{i=3,5,7, \ldots} \sqrt{2} E_{g i} \sin \left(i \omega_{n} t-\varphi_{i}\right)
$$

Neglecting the energy variations in the connection inductor and all the losses, the power reflected in the DC-link is $v_{D C}=$ $e_{g} i_{g}$ with $e_{g}$ and $i_{g}$ the grid voltage and current respectively and $i_{G T}$ the grid-side DC-link current. In order to calculate $i_{G T}$ the DC-link voltage is considered approximately constant and equal to the reference voltage, which is usually set $15 \%$ over the diode voltage $v_{D C} \approx 1.15 \sqrt{2} E_{g 1}$. The grid current is assumed to be properly regulated; it is perfectly sinusoidal and has unity power factor $i_{g}=\sqrt{2} I_{g}^{r e f} \sin \left(\omega_{n} t\right)$. Taking into account the trigonometric identity $2 \sin (a) \sin (b)=\cos (a-$ $b)-\cos (a+b)$, the grid-side DC-link current is approximately:

$$
\begin{aligned}
i_{G T} \approx \frac{I_{g}^{\text {ref }}}{1.15 \sqrt{2}} & {\left[1+\sum_{j=2,4,6, \ldots} \frac{E_{g j+1}}{E_{g 1}} \cos \left(j \omega_{n} t-\varphi_{j+1}\right)\right.} \\
& \left.-\sum_{j=2,4,6, \ldots} \frac{E_{g j-1}}{E_{g 1}} \cos \left(j \omega_{n} t-\varphi_{j-1}\right)\right]
\end{aligned}
$$

It can be seen that the grid-side DC-link current always has a pulsating component at twice the grid frequency $2 \omega_{n}$. Moreover, with distorted voltages, the grid-side DC-link current has harmonic components in the even multiples of the 
fundamental frequency. Taking into account the slow variation of $I_{g}^{r e f}=P_{g}^{r e f}\left(\omega_{t}\right) / E_{g 1}$, the following analysis on the filtering options for the DC-link voltage will consider that the grid currents are sinusoidal with unity power factor and the grid-side DC-link current is approximately (21).

\section{Filtering Options FOR THE DC-LINK VOlTAGE}

This section provides an evaluation of filters in the feedback loop to minimize the reflected ripple torque in the wind turbine. As a result of the comparative analysis, Notch filter, ARF and MAF prove to be more advantageous. The following derivations can be applied to the present case where the DClink is controlled by the machine-side converter and also to the case where the DC-link is controlled by the the grid-tie converter.

\section{A. Padé Approximant for the Different Filters}

The previous formulas (1) and (2) were derived by assuming the feedback filter as a first order system. However, in the following, higher order filters will be used and a mechanism for a fair comparison should be selected. One possible candidate could be the bandwidth as defined for the first order system. This is the frequency at which the gain is reduced to $3 \mathrm{~dB}$ and the phase delay becomes larger than 45 degrees [32]. However, in higher order systems, this does not happen at the same frequency and the conservative approach would be to select the lowest frequency [32]. Another plausible mechanism for comparison is to make all the filters have the same rise time $t_{r}$, defined as the time required to go from $10 \%$ to $90 \%$ in the unit-step response. This would imply that all the filters have similar responses in the time domain. However, the analytical formulas to calculate the rise time of the high order filters are not straightforward.

The Padé approximant allows a fraction of polynomials $p_{n, d}(s)$ to be obtained that is an optimal approximation of a function $f(s)$ [39]. In the Padé approximant, $n$ and $d$ refer to the order of the numerator and denominator of the polynomials. The Padé approximant $p_{n, d}(s)$ has the same Taylor series expansion, up to $n+d$ order, as the approximated function $f(s)$. The Padé approximant of order $n=0$ and $d=1$ around $s=0$ corresponds to:

$$
p_{0,1}(s)=\frac{1}{\tau_{f f} s+1} \mid p_{0,1}(0)=f(0), p_{0,1}^{\prime}(0)=f^{\prime}(0)
$$

It allows a high order system to be approximated to a first order system with the same behavior at low frequency (around $s=j \omega \approx 0)$.

1) Butterworth Filter: The transfer function of a second order Butterworth filter corresponds to this:

$$
G_{B w 2 n d}(s)=\frac{1}{\frac{s^{2}}{\omega_{c}^{2}}+\frac{\sqrt{2} s}{\omega_{c}}+1}
$$

where $\omega_{c}$ is the cut off frequency defined for $-3 \mathrm{~dB}$. The frequency responses of the $1^{\text {st }}$ order and $2^{\text {nd }}$ order Butterworth filters roll off at $20 \mathrm{~dB}$ and $-60 \mathrm{~dB}$ per decade respectively,
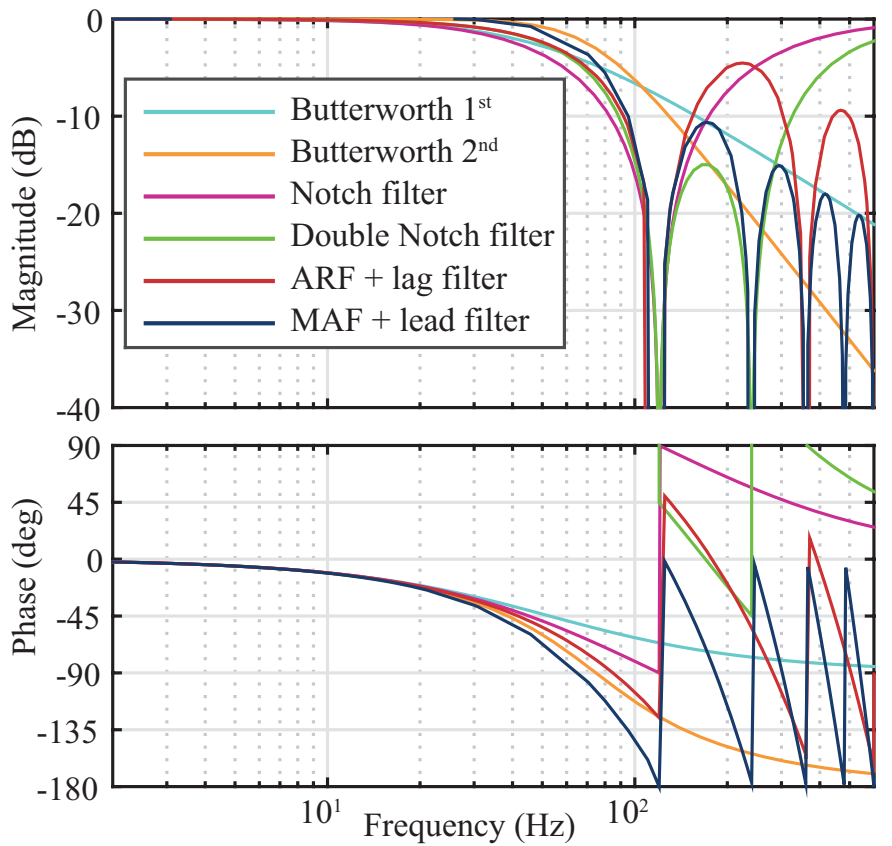

Fig. 4: Frequency response of the different filtering options. The responses of the $1^{\text {st }}$ order and $2^{\text {nd }}$ order Butterworth filters roll off at $20 \mathrm{~dB}$ and $-60 \mathrm{~dB}$ per decade respectively. The response of the notch filter has a narrow notch that cancels the component at $\omega_{\text {notch }}=2 \omega_{n}$, first harmonic component of the grid-side DC-link current (21). The double notch filter has two narrow notches that cancel the components at $2 \omega_{n}$ and $4 \omega_{n}$, main components of (21). The ARF has narrow notches that cancel the components at all the odd frequencies multiple of $\omega_{A R F}=2 \omega_{n}$. Finally, the MAF has narrow notches that cancel the components at all the frequencies multiple of $\omega_{M A F}=2 \omega_{n}$, all the components of the grid-side DC-link current (21).

and are shown in Fig. 4. The Padé approximant $p_{n, d}(s)$ of (23) corresponds to:

$$
p_{B w 2 n d 0,1}(s)=\frac{1}{\frac{\sqrt{2}}{\omega_{c}} s+1}
$$

Therefore, at low frequency the second order Butterworth filter behaves as the first order system (24). Intuitively, it can be seen that, for low frequency $\left(\omega<\omega_{c}\right)$, the term $s^{2} / \omega_{c}^{2}$ can be neglected in the denominator of (23).

2) Notch Filter: The notch filter adds a double zero in the numerator of (23) to annul the output at the notch frequency $\omega_{\text {notch }}$, as shown in Fig. 4. The transfer function of the notch filter is:

$$
G_{\text {notch }}(s)=\frac{\frac{s^{2}}{\omega_{\text {notch }}^{2}}+1}{\frac{s^{2}}{\omega_{\text {notch }}^{2}}+\frac{2 \xi s}{\omega_{\text {notch }}}+1}
$$

The frequency response results in a narrow notch that will cancel the component at $\omega_{\text {notch }}$, as shown in Fig. 4 . The notch can safely be very narrow, as the notch frequency is related to the grid frequency, which is a very stable magnitude and which is continuously estimated in the synchronization PLL. The Padé approximant of (25) corresponds to:

$$
p_{\text {notch } 0,1}(s)=\frac{1}{\frac{2 \xi}{\omega_{\text {notch }}} s+1}
$$


which is the same as (24) because the zeros of the notch in (25) only have an effect around $\omega_{\text {notch }}$ and do not affect the low frequency region.

The notch frequency must be located at the first harmonic component of the grid-side DC-link current (21), which is $2 \omega_{n}$. If there is a voltage with low order harmonics, the notch filter may be unable to cancel the other alternating components. In such cases, several sections tuned to the different component can be used at the expense of additional computations and smaller notch widths. The transfer function of multiple notch filter is:

$$
G_{n n o t c h}(s)=\prod_{k=2,4,6 \ldots} \frac{\frac{s^{2}}{k^{2} \omega_{n}^{2}}+1}{\frac{s^{2}}{k^{2} \omega_{n}^{2}}+\frac{2 \xi_{k} s}{k \omega_{n}}+1}
$$

Selecting $\xi=\xi_{j}$, the Padé approximant $p_{n, d}(s)$ of (27) corresponds to:

$$
p_{\text {nnotch } 0,1}(s)=\frac{1}{\left(\sum_{k=2,4,6, \ldots} \frac{1}{k \omega_{n}}\right) 2 \xi s+1}
$$

Fig. 4 shows the frequency response of the double notch filter. It can be seen that it has two narrow notches that cancel the components at $2 \omega_{n}$ and $4 \omega_{n}$, main harmonic components of the grid-side DC-link current (21).

3) Antiresonant filter: The frequency response of the ARF is shown in Fig. 4. The ARF can be defined in the continuous domain as the sum of a original signal $u(t)$ and a delayed signal $u(t-T)$ as:

$$
A R F(t)=\frac{1}{2}\left[u(t)+u\left(t-\frac{T_{d}}{2}\right)\right]
$$

where $T_{d}$ is the window period. Applying the Laplace transform, the transfer function of the ARF in the continuous domain is:

$$
G_{A R F}(s)=\frac{1}{2}\left(1+e^{-\frac{T_{d}}{2} s}\right)=\cosh \left(\frac{T_{d}}{4} s\right) e^{-\frac{T_{d}}{4} s}
$$

It is clear that the term $1 / 2$ makes the DC gain unity. Substituting $s=j \omega$ and remembering that $\cosh j \omega=\cos \omega$, the frequency response of the continuous ARF is:

$$
G_{A R F}(j \omega)=\cos \left(\frac{T_{d}}{4} \omega\right) e^{-j \frac{T_{d}}{4} \omega}
$$

The frequency response of the ARF in (31) is composed of two factors and is shown in Fig. 4. The cosine function of the first factor has periodic notches at all the odd frequencies multiple of $\omega_{A R F}=2 \pi / T_{d}$, which will be used to cancel high frequency components, and has no phase delay (real part). The second factor is a pure time delay of $T_{d} / 4$. The Padé approximant $p_{n, d}(s)$ of (34) is:

$$
p_{A R F 0,1}(s)=\frac{1}{\frac{T_{d}}{4} s+1}
$$

Intuitively, (35) can be explained by approximating the sinc function to the unity for low frequency and doing the series expansion of the pure time delay $e^{-s T_{d} / 4}$.

4) Moving average filter: The moving average filter (MAF) can be defined in the continuous domain as an integral with varying limits [22] as:

$$
\begin{array}{r}
M A F(t)=\frac{1}{T_{w}} \int_{t-T_{w}}^{t} u(t) d \tau \\
=\frac{1}{T_{w}}\left(\int_{0}^{t} u(t) d \tau-\int_{0}^{t-T} u(t) d t\right)
\end{array}
$$

where $T_{w}$ is the window period. Applying the Laplace transform, the transfer function of the MAF in the continuous domain is:

$$
\begin{array}{r}
G_{M A F}(s)=\frac{1}{T_{w}}\left(\frac{1}{s}-\frac{e^{-T_{w} s}}{s}\right)=\frac{1-e^{-T_{w} s}}{T_{w} s} \\
=\frac{\sinh \left(\frac{T_{w}}{2} s\right)}{\frac{T_{w}}{2} s} e^{-\frac{T_{w}}{2} s}
\end{array}
$$

Substituting $s=j \omega$ and remembering that $\sinh j \omega=$ $j \sin \omega$, the frequency response of the continuous MAF is:

$G_{M A F}(j \omega)=\frac{\sin \left(\frac{T_{w}}{2} \omega\right)}{\frac{T_{w}}{2} \omega} e^{-\frac{T_{w}}{2} j \omega}=\operatorname{sinc}\left(\frac{\omega}{\omega_{M A F}}\right) e^{-j \frac{\omega}{\omega_{M A F}}}$

The frequency response of the MAF in (35) consists of two factors. The sinc function of the first factor has periodic notches at all the frequencies multiple of $\omega_{M A F}=2 \pi / T_{w}$ and has no phase delay (real part). The second factor is a pure time delay of $T_{w} / 2$. The Padé approximant $p_{n, d}(s)$ of (34) is:

$$
p_{M A F 0,1}(s)=\frac{1}{\frac{T_{w}}{2} s+1}
$$

Intuitively, (35) can be explained by approximating the sinc function to the unity and the series expansion of the pure time delay $e^{-s T_{w} / 2}$.

The frequency response of the MAF is shown in Fig. 4. It can be seen that when selecting $\omega_{M A F}=2 \omega_{n}$, the notches are located at the same frequencies as the components of the grid-side DC current (21). Therefore, the MAF will be very effective when the grid voltages are highly distorted.

\section{B. Considerations on Discretization}

The discrete implementation of the Butterworth filter (23) should employ the bilinear rule (Tustin method) with prewarping at the frequency double the grid frequency. Similarly, the discrete implementation of notch filter (25) should employ the bilinear rule (Tustin method) with pre-warping at $\omega_{\text {notch }}$ in order to preserve the notch characteristics.

The usual discrete version of the ARF results from discretizing (30) [40] and is:

$$
G_{A R F}(z)=\frac{1}{2}\left(1+z^{-N_{d 2}}\right)
$$


with $N_{d 2}=T_{d} /\left(2 T_{s}\right)$ the window duration measured in number of samples. Because the DSP is optimized for multiply and accumulate operations and uses circular buffers, digital filters have very simple and efficient implementation. In cases where $N_{d 2}$ does not result in an integer number, it is clear that it should be rounded to the closest integer. In general, $T_{s}$ is very small and $T_{w}$ is related to the grid period, which is a very constant magnitude [15]. Hence, provision should be done to obtain an integer $N_{d 2}=T_{d} /\left(2 T_{s}\right)$. For non integer $N_{d 2}=T_{d} /\left(2 T_{s}\right)$ the output of the continuous ARF (33) can be written as follows:

$$
\begin{gathered}
y(s)=\frac{1}{2}\left(u(s)+e^{N_{f d 2} T_{s} s} e^{-\left(N_{d 2}-N_{f d 2}\right) T_{s}} u(s)\right)= \\
\frac{1}{2}\left(u(s)+e^{-N_{f d 2} T_{s} s} \mathcal{L}\left\{u\left(t-\left(N_{d 2}-N_{f d 2}\right) T_{s}\right)\right\}\right)
\end{gathered}
$$

with $N_{f d 2}=$ floor $\left[T_{d} /\left(2 T_{s}\right)\right]$. Using linear interpolation between $u\left(k T_{s}\right)$ and $u\left(k T_{s}-T_{s}\right)$, the following approximation can be made:

$$
\begin{array}{r}
u\left(t-\left(N_{d 2}-N_{f d 2}\right) T_{s}\right) \\
\approx u(k)\left(\left(1-N_{d 2}+N_{f d 2}\right)\right)+u(k-1)\left(N_{d 2}-N_{f d 2}\right)
\end{array}
$$

Substituting (38) in (39), the discrete transfer function of the ARF filter with non-integer $N_{d 2}$ is as follows:

$$
\begin{aligned}
G_{A R F}(z)=\frac{1}{2}[1+ & \left(1-N_{d 2}+N_{f d 2}\right) z^{-N_{f d 2}} \\
& \left.+\left(N_{d 2}-N_{f d 2}\right) z^{-N_{f d 2}-1}\right]
\end{aligned}
$$

It can be seen that when $N_{d 2}$ is close to $N_{f d 2},(40)$ is close to (37), and when $N_{d 2}$ is close to $N_{d 2}=N_{f d 2}+1$, (40) is close to (37) plus a unit delay.

The usual discrete version of the MAF results from discretizing (34) by using zero-pole matching [40] and is:

$$
G_{M A F}(z)=\frac{1}{N_{w}} \frac{1-z^{-N_{w}}}{1-z^{-1}}
$$

with $N_{w}=T_{w} / T_{s}$ the window duration in number of samples. As for the case of the ARF, when $N_{w}$ does not result in an integer number it is clear that it should be rounded to the closest integer and provision should be made to obtain an integer. If it is not possible to do so, [41] proposes that a weight mean value between the discrete MAF for the ceiling value of $N_{c}=\operatorname{ceiling}\left(T_{w} / T_{s}\right)$ and $N_{f}=$ floor $\left(T_{w} / T_{s}\right)$ be used, while in [42], linear interpolation is used. As with the ARF, when $N_{w}=T_{w} / T_{s}$ is not an integer, the output of the continuous MAF (33) can be written as follows:

$$
\begin{array}{r}
y(s)=\frac{1}{T_{w}}\left(\frac{1}{s} u(s)-\frac{e^{-N_{f} T_{s} s}}{s} e^{-\left(N_{w}-N_{f}\right) T_{s}} u(s)\right)= \\
\frac{1}{T_{w}}\left(\frac{1}{s} u(s)-\frac{e^{-N_{f} T_{s} s}}{s} \mathcal{L}\left\{u\left(t-\left(N_{w}-N_{f}\right) T_{s}\right)\right\}\right)
\end{array}
$$

As previously, using linear interpolation between $u\left(k T_{s}\right)$ and $u\left(k T_{s}-T_{s}\right)$ the following approximation can be made:
$u\left(t-\left(N_{w}-N_{f}\right) T_{s}\right) \approx u(k)\left(\left(1-N_{w}+N_{f}\right)\right)+u(k-1)\left(N_{w}-N_{f}\right)$

Finally, discretizing by using zero-pole matching [40] and substituting in (42), the discrete transfer function of the MAF filter with non-integer $N_{w}$ is obtained as follows:

$$
=\frac{1}{N_{w}} \frac{1-\left(1-N_{w}+N_{f}\right) z^{-N_{f}}-\left(N_{w}-N_{f}\right) z^{-N_{f}-1}}{1-z^{-1}}
$$

It can be seen that, when $N_{w}$ is close to $N_{f}$, (44) is close to (41), and when $N_{w}$ is close to $N_{w}=N_{f}+1$, (44) is close to (41) plus an additional unit delay.

\section{Lead-lag filter for bandwidth selection in the MAF and $A R F$}

For a fair comparison, all the filters must result in the same bandwidth (1) with the same time constant $\tau_{f f}$. The main source of perturbation in (20) is at double the grid frequency, and the notches of the notch filter (25), ARF and MAF should be located at that frequency $2 \omega_{n}$. Thus, the parameters for the notch filter, ARF and MAF should be selected as:

$$
\omega_{\text {notch }}=\underset{(45 \mathrm{a})}{2 \omega_{n}} \quad T_{d}=\frac{1}{2 f_{n}} \quad T_{w}=\frac{1}{2 f_{n}}
$$

The equivalent time constants for the Butterworth filter, notch filter, ARF and MAF correspond to:

$$
\tau_{f f}^{B w 2 n d}=\frac{\sqrt{2}}{\omega_{c}} \tau_{f f}^{\text {notch }}=\underset{(46 \mathrm{a})}{\frac{\xi}{2 \pi f_{n}}} \tau_{f f}^{A R F}=\frac{1}{8 f_{n}} \quad \tau_{f f}^{M A F}=\frac{1}{4 f_{n}}
$$

respectively. Finally, the bandwidths achieved in the DClink voltage closed loop control are:

$$
\begin{gathered}
f_{b w S O}^{B w 2 n d}=\frac{\omega_{c}}{2 \pi a\left(\tau_{c c} \omega_{c}+\sqrt{2}\right)} \quad f_{b w S O}^{n o t c h}=\frac{\omega_{n}}{2 \pi a\left(\tau_{c c} \omega_{n}+\xi\right)}(47 \mathrm{~b}) \\
f_{b w S O}^{A R F}=\frac{4 f_{n}}{2 \pi a\left(\tau_{c c} 4 f_{n}+1\right)}\left(\begin{array}{l}
\text { (47c) } \\
\text { (4) }
\end{array}\right.
\end{gathered}
$$

It can be seen that the bandwidth is selectable for the Butterworth and notch filters by varying $\omega_{c}$ and $\xi$ respectively. However, the bandwidth for the ARF and MAF is fixed and determined by $f_{n}$.

The large equivalent delay of the MAF in (46d) can result in insufficient bandwidth in the DC-voltage control. A lead filter can be used to increase the filter speed:

$$
L D F(s)=\frac{T_{n l d} s+1}{T_{d l d} s+1}
$$


with $T_{n l d}$ and $T_{d l d}$ the numerator and denominator time constants. The combined MAF (34) and lead filter (48) must have a Padé approximant equivalent to the first order system that results in the selected bandwidth of the DC-link voltage control. To achieve this aim, the zero of the lead network is used to compensate the phase delay in (36) $T_{n u m}=T_{w} / 2$. The time constant $T_{d l d}$ is required to obtain the selected bandwidth $f_{b w S O}$ :

$$
T_{d l d}=\frac{1}{2 \pi a f_{b w S O}}-\tau_{c c}
$$

The maximum bandwidth is limited and should be verified by simulation. Simulations showed that a higher order lead filter results in oscillatory behavior and, thus, the first order lead filter (48) is sufficient for increasing the bandwidth.

If the bandwidth achieved by the ARF is excessively large, it can be reduced by using a lag filter:

$$
L G F(s)=\frac{1}{T_{d l g}+1}
$$

As with the combined MAF and lead filter, the combined ARF (29) and lag filter (50) must have a Padé approximant equivalent to the first order system that results in the selected bandwidth of the DC-link voltage control. Using (46c) and (2), the resulting value is obtained:

$$
T_{d l g}=\frac{1}{2 \pi a f_{b w S O}}-\tau_{c c}-\tau_{f f}^{A R F}
$$

The discrete implementation of (48) and (50) should be obtained by using bilinear rule (Tustin method) with prewarping at $\omega=\omega_{n}$ in order to preserve the characteristics at low frequency.

\section{Simulation RESUlts}

Table I shows all the data of the set-up used for the filter comparison, simulations and experiments. The current loops of the PMSG vector control were tuned according to the technical optimum criterion. Due to robustness concerns, the current loop bandwidth was reduced to $75 \%$ of the previous values while still maintaining a bandwidth of $560 \mathrm{~Hz}$. This results in a time delay in the current control of $\tau_{c c}=0.28$ $\mathrm{ms}$, the achieved DC-voltage control bandwidth for the MAF and ARF according to (47c) and (47d) are respectively 14.81 $\mathrm{Hz}$ and $27.86 \mathrm{~Hz}$. A reduced bandwidth prevents the DClink voltage control from canceling the pulsation of twice the grid frequency. At the same time, the bandwidth should not be so small to require large capacitors in order to avoid excessive overshoot [43]. The bandwidth achieved by the ARF is acceptable, but the bandwidth for the MAF falls short, making necessary to use the auxiliary lead filter. The DC-voltage control bandwidth selected for simulations and experiments is $20 \mathrm{~Hz}$ leading to a rise time of $28.25 \mathrm{~ms}$, which can be considered reasonably fast [43].

Fig. 5 shows the Bode diagrams of the DC-link voltage control for the different filtering options. It can be seen that all of them result in the selected bandwidth of the DClink voltage control with amplitude $-3 \mathrm{~dB}$ at $15.7 \mathrm{~Hz}$ and
TABLE I: Parameters of the experimental set-up.

Machine side converter

\begin{tabular}{lcc}
\hline \hline Rated power & $S_{n}$ & $2.2 \mathrm{kVA}$ \\
Rated ac voltage & $V_{n}$ & $380 \mathrm{~V}$ \\
Rated frequency & $f_{n}$ & $60 \mathrm{~Hz}$ \\
dc link voltage & $v_{D C}$ & $200 \mathrm{~V}$ \\
Sampling frequency & $f_{s}$ & $15 \mathrm{kHz}$ \\
PWM frequency & $f_{s w}$ & $15 \mathrm{kHz}$ \\
LC-filter & & \\
\hline \hline Capacitor & $C_{f}$ & $4.7 \mu \mathrm{F}$ \\
Inductor & $L_{g}$ & $1.8 \mathrm{mH}$ \\
Damping resistor & $R_{d}$ & $6 \Omega$ \\
Permanent Magnet Synchronous Generator & & \\
\hline \hline Direct inductance & & \\
Quadrature inductance & $L_{d}$ & $1.8 \mathrm{mH}$ \\
Magnetic flux & $L_{q}$ & $1.8 \mathrm{mH}$ \\
Inertia & $\lambda$ & $1.8 \mathrm{~T}$ \\
Pole pairs & $I$ & $0.0062 \mathrm{kgm}^{2}$ \\
\hline
\end{tabular}
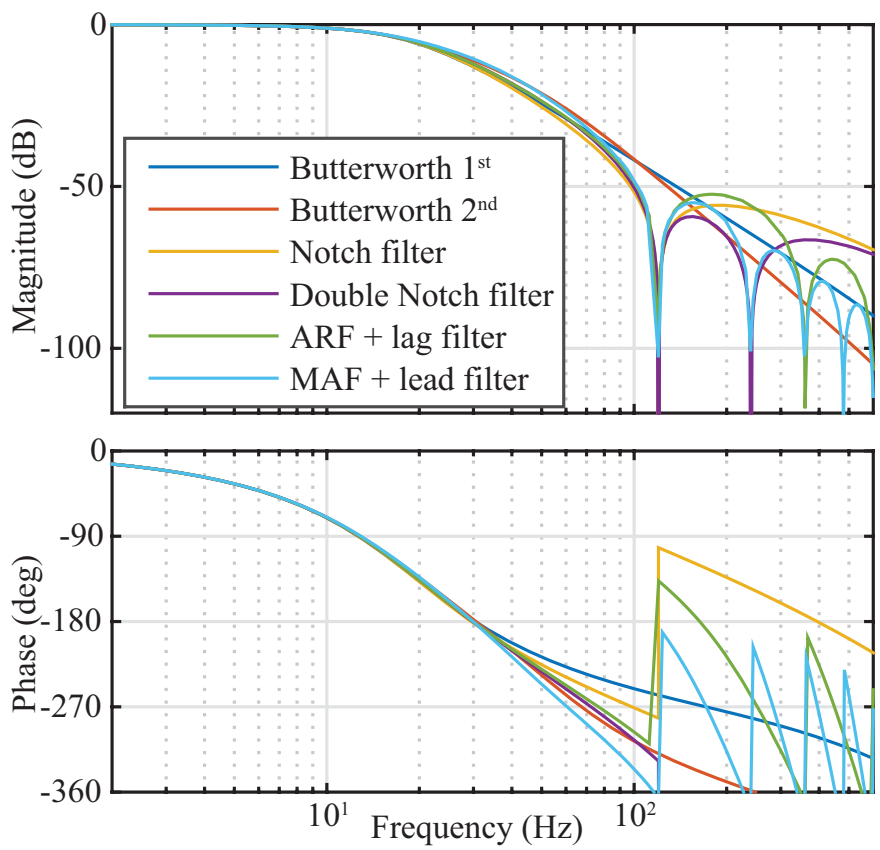

Fig. 5: Frequency response of the DC-link voltage control for the different filtering options. All the Bode plots result in the selected bandwidth of the DC-link voltage control with the same amplitude -3 $\mathrm{dB}$ at $15.7 \mathrm{~Hz}$ and phase -45 degrees at $6.47 \mathrm{~Hz}$, which allows a fair comparison between the different filtering options. All the responses result in the same low frequency behavior and, for higher frequencies, the response of the DC-link voltage control presents notches: at $2 \omega_{n}$ in the notch filter, at $2 \omega_{n}$ and $4 \omega_{n}$ in the double notch filter, at odd multiples of $2 \omega_{n}$ in the ARF+lag filter, and at all the multiples of $2 \omega_{n}$ in the MAF+lead filter.

phase -45 degrees at $6.47 \mathrm{~Hz}$, which allows a fair comparison between the different filtering options. These frequencies are not coincident, as the filters have high order. Therefore, it can be considered that all the responses result in the same low frequency behavior. For higher frequencies, the response of the DC-link voltage control presents notches: at $2 \omega_{n}$ in the notch filter, at $2 \omega_{n}$ and $4 \omega_{n}$ in the double notch filter, at odd multiples of $2 \omega_{n}$ in the ARF+lag filter, and at all the multiples of $2 \omega_{n}$ in the MAF+lead filter. 

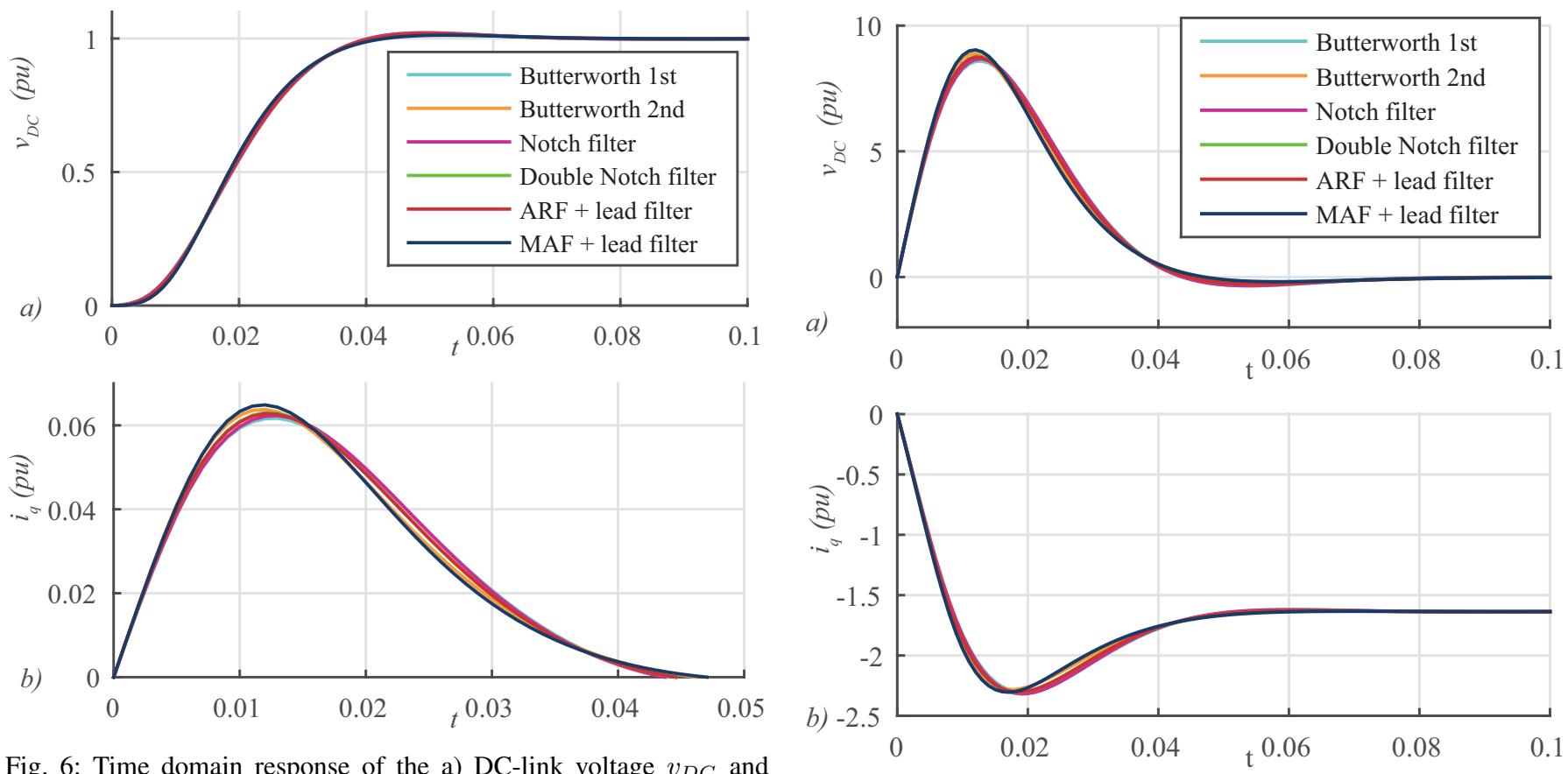

Fig. 6: Time domain response of the a) DC-link voltage $v_{D C}$ and b) quadrature current $i_{q}$ to the unit reference step for the different filtering options in the DC-link control. The final value of the gridside DC-link current step is constant with no superimposed harmonic content. As all the filtering options result in the selected bandwidth of the DC-link voltage control for a fair comparison, the time domain responses to steps variations are very close to each other. The quadrature current $i_{q}$ of the MAF+lead filter case has slightly higher overshoot and is slightly faster due to the derivative action of the lead filter.

As all the filtering options result in the selected bandwidth of the DC-link voltage control for a fair comparison, it is expected that the time domain responses to steps variations will be also equivalent. Fig. 6a shows the time response to the unit step change in the voltage reference and Fig. $6 \mathrm{~b}$ shows the quadrature current $i_{q}$. The PI controller output is the quadrature current reference $i_{q}^{r e f}$. The current $i_{q}$ is approximately a delayed version of $i_{q}^{r e f}$ by $\tau_{c c}$ due to the fast current control. It can be seen that the responses of all the filtering options are very close to each others. Considering $a^{\frac{3}{2}}$ in (2), the resulting value $12.87 \mathrm{~Hz}$ is very close to 0.35 over the rise time $0.35 /(28 \mathrm{~ms})=12.45 \mathrm{~Hz}$. The quadrature current $i_{q}$ response of the MAF+lead filter case has slightly higher overshoot and is slightly faster due to the derivative action of the lead filter. Fig. 7a shows the time response to unit step change in the grid-side DC-link current (load step) and Fig. 7b shows the quadrature current $i_{q}$. The final value of the gridside DC-link current step is constant with no superimposed harmonic content. For this case, the responses are also close to each other. The response of the MAF+lead filter case has slightly higher overshoot as is slightly due to the derivative action of the lead filter.

Simulations were done using Matlab/Simulink blocks. A PLL uses the voltage measurements at the PMSG terminals to estimate the rotor position and speed [44]. The grid-side converter was assumed to have perfect sinusoidal regulation. Hence, the grid-side DC-current was synthesized to be like

Fig. 7: Time domain response of the a) the DC-link voltage $v_{D C}$ and b) quadrature current $i_{q}$ to the load step (grid-side DC-link current) in the DC-link control. The final value of the grid-side DC-link current step is constant with no superimposed harmonic content. As all the filtering options result in the selected bandwidth of the DC-link voltage control for a fair comparison, the time domain responses to steps variations are very close to each other. The load step response of the MAF+lead filter case has slightly higher overshoot as is slightly faster due to the derivative action of the lead filter.

\section{(21) through a controlled current source.}

In order to evaluate the performance in steady state, it was assumed that the grid voltage was heavily distorted with harmonics $3^{\text {rd }}\left(30 \% / 10^{\circ}\right), 5^{\text {th }}\left(20 \% / 20^{\circ}\right)$ and $7^{\text {th }}\left(10 \% / 30^{\circ}\right)$. The average value of the grid-side DC-current is $1.5 \mathrm{~A}$. For the comparative analysis, torque ripple will also be represented (in parentheses) normalized to the value corresponding to the Butterworth $1^{\text {st }}$ order filter. Fig. 8 shows the simulation results of the different filtering options during steady state. It can be seen that Butterworth $1^{\text {st }}$ order and $2^{\text {nd }}$ order filters result in highest torque ripple with $0.3479 \mathrm{Nm}(100 \%$ normalization value) and $0.2294 \mathrm{Nm}(65.94 \%)$, respectively. The rest of the filters have similar performance, the best being the MAF, with $0.0789 \mathrm{Nm}(22.68 \%)$, followed by the double notch filter with $0.0869 \mathrm{Nm}(24.98 \%)$, the ARF with $0.1060 \mathrm{Nm}(30.47 \%)$ and finally the notch filter with $0.1194 \mathrm{Nm}(34.32 \%)$. It is clear that the filters with a notch at $2 \omega_{n}$ result in the maximum reduction of torque ripple. In addition, the double notch filter has a notch at $4 \omega_{n}$, which cancels harmonics coming form the $3^{\text {rd }}$ and $5^{\text {th }}$ voltage harmonics and produces better results than the ARF. The electrical torque $T_{e}$ is proportional to the $q$ current. As the $d$-current is regulated to be zero, the $q$-current is approximately the amplitude of the PMSM phase-current. Therefore, the more torque ripple the more harmonic content in the PMSM phase-current. This can be seen in Fig. 8, where the values of the PMSM phase-current THD are shown. 


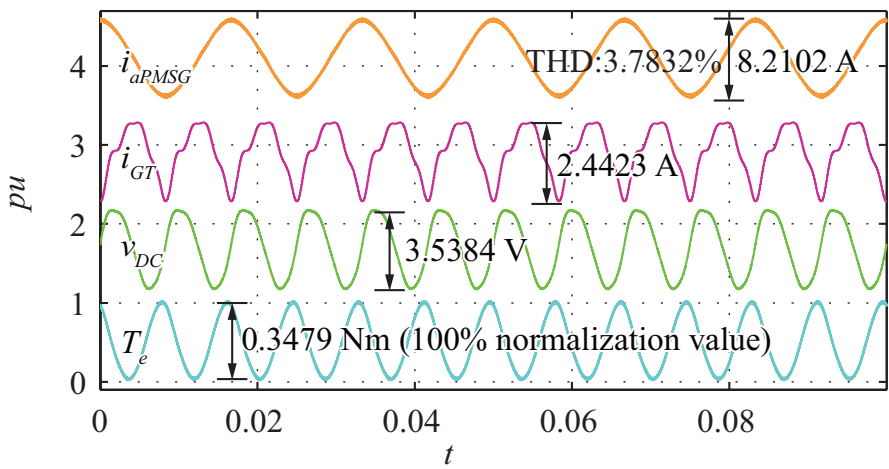

(a) Butterworth $1^{\text {st }}$ order filter.

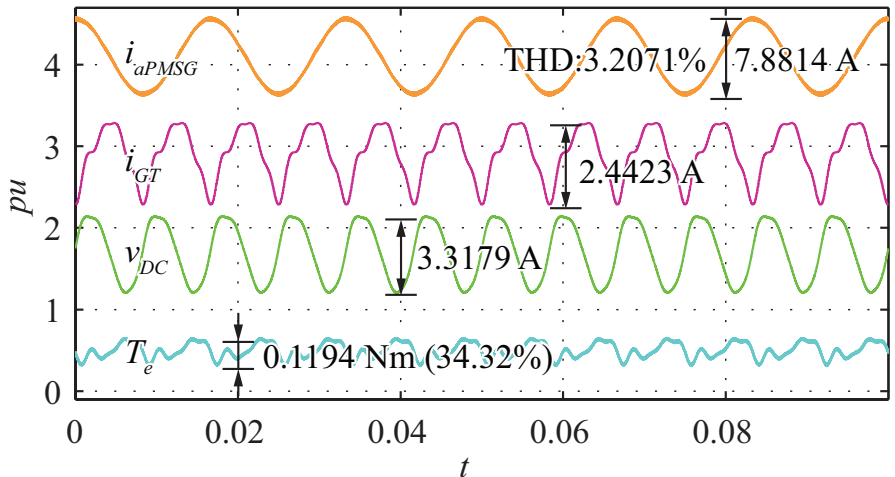

(c) Notch filter.

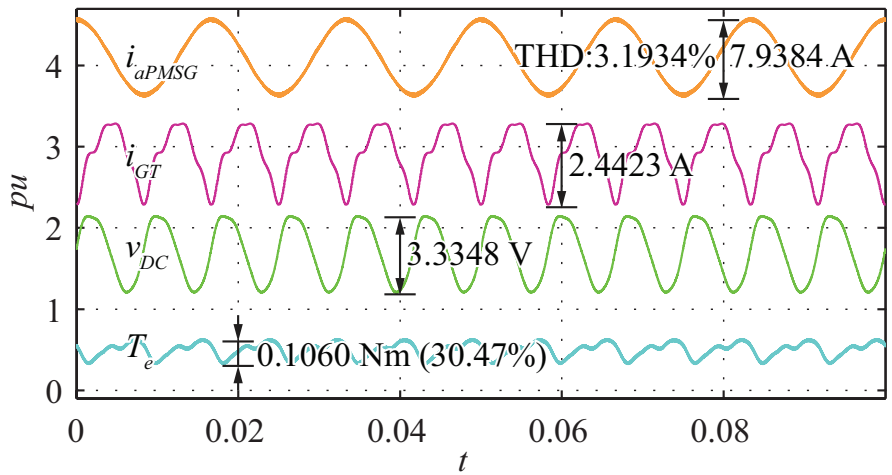

(e) ARF plus lag filter.

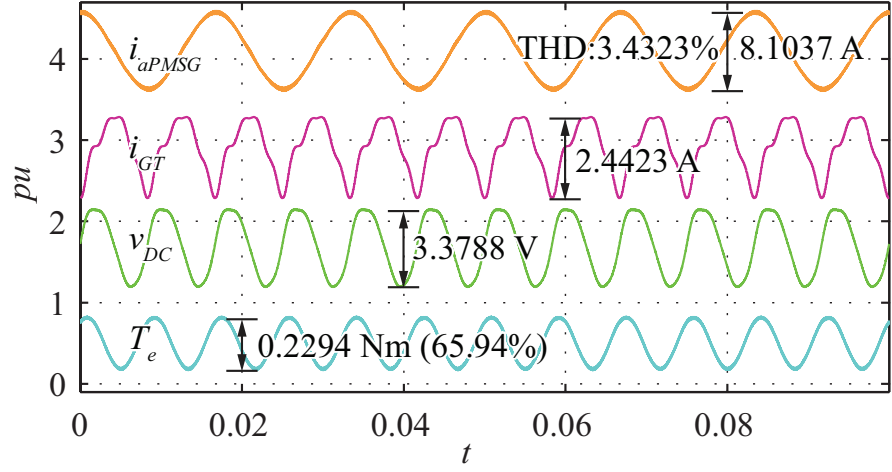

(b) Butterworth $2^{\text {nd }}$ order filter.

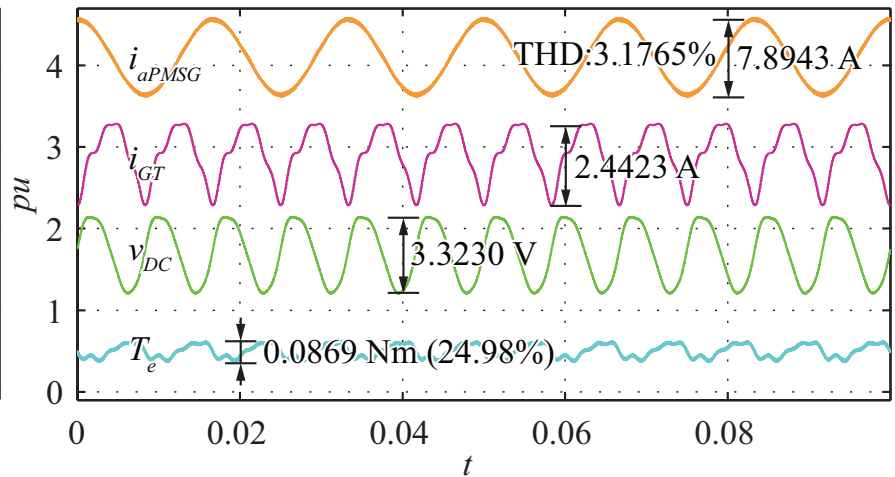

(d) Double Notch filter.

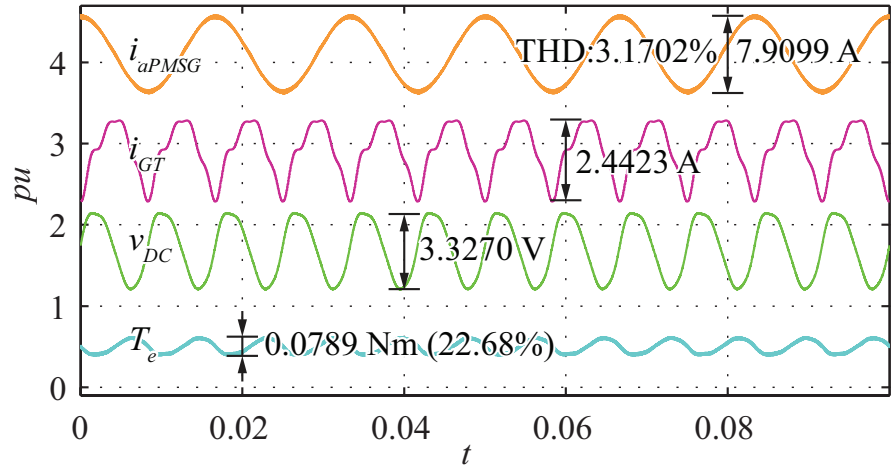

(f) MAF plus lead filter.

Fig. 8: Simulation results: steady state responses of the different filtering options. Torque ripple is also represented (in parentheses) normalized to the value corresponding to the Butterworth $1^{\text {st }}$ order filter. Butterworth $1^{\text {st }}$ order $(100 \%$ normalization value $)$ and $2^{\text {nd }}$ order $(65.94 \%)$ filters result in highest torque ripple. The rest of the filters have similar performance, the best being the MAF (22.68\%), followed by the double notch filter $(24.98 \%)$, the ARF $(30.47 \%)$ and finally the notch filter $(34.32 \%)$. The filters with a notch at $2 \omega_{n}$ result in the maximum reduction of torque ripple. The double notch filter has a notch at $4 \omega_{n}$, which cancels harmonics coming form the $3^{\text {rd }}$ and $5^{\text {th }}$ voltage harmonics and produces better results than the ARF.

Fig. 9 shows the simulations results of the different filtering options for the transients. The tests consists of applying a step of $1.5 \mathrm{~A}$ in the grid-side DC-current. The grid-current reference depends on the slowly-varying wind-turbine speed and in practice transients of the grid-side DC-current are much smoother than a sharp step, see Subsection II-D. For this case, the grid voltage was perfectly sinusoidal. As all the filters result in the selected bandwidth of the DC-link voltage control for a fair comparison, the transient responses for all the cases are very similar to each other as in the filter comparison. The transient duration, measured in the DC-voltage, is in all cases approximately the same: $92.62 \mathrm{~ms}$. For the comparative analysis, torque overshoot will also be represented (in parentheses) normalized to the value corresponding to the Butterworth $1^{\text {st }}$ order filter. The torque overshoot for the Butterworth $1^{\text {st }}$ order (4.3968 Nm 100\% normalization value) and $2^{\text {nd }}$ order (4.3218 $\mathrm{Nm} 98.29 \%$ ) filters is higher because of the presence of torque ripple. For the rest of the filters, the MAF (4.2748 Nm 97.22\%) 


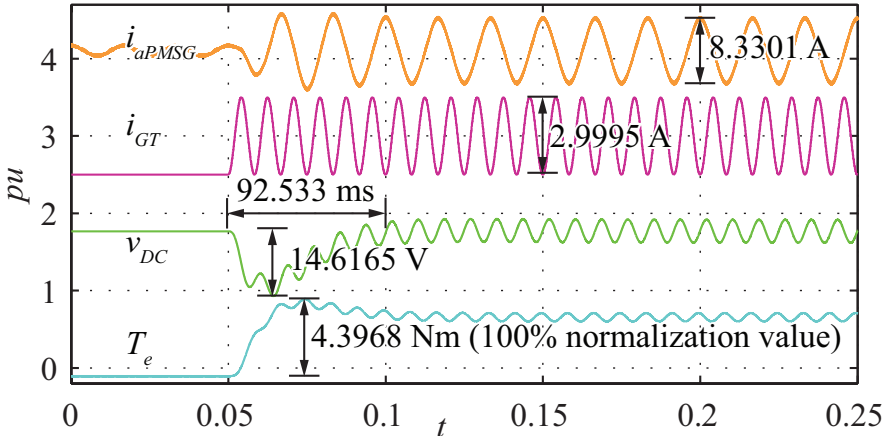

(a) Butterworth $1^{\text {st }}$ order filter.

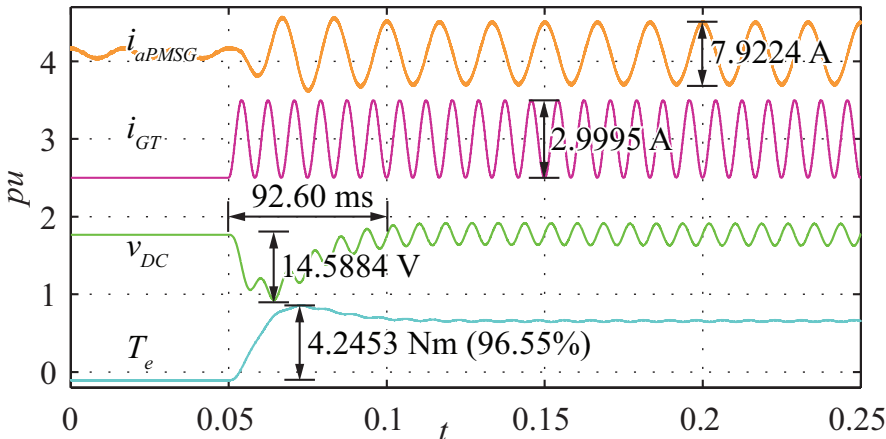

(c) Notch filter.

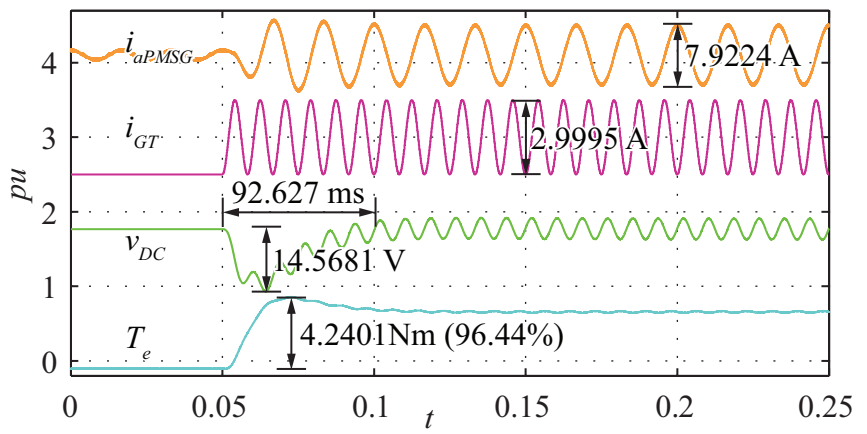

(e) ARF plus lag filter.

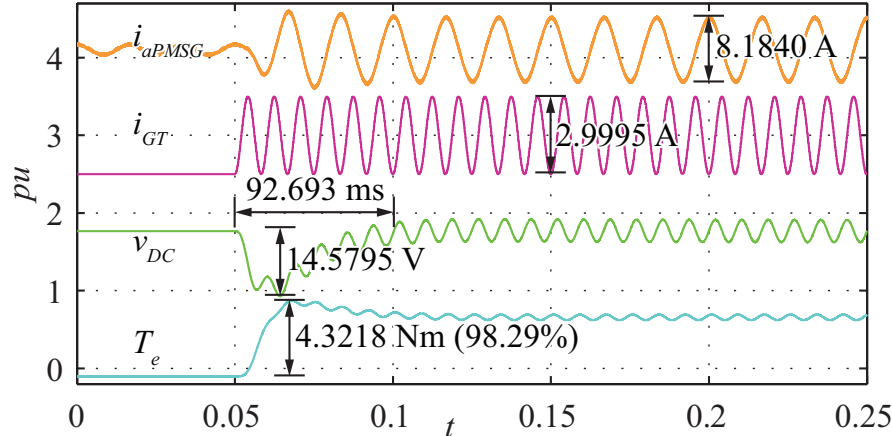

(b) Butterworth $2^{\text {nd }}$ order filter.

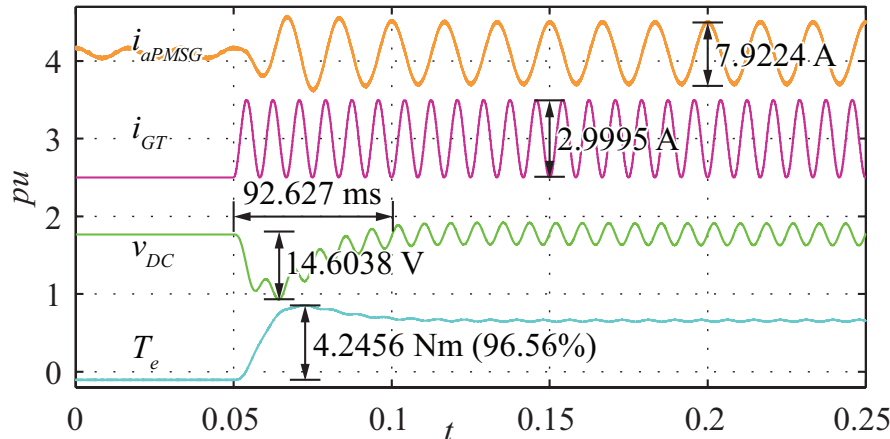

(d) Double Notch filter.

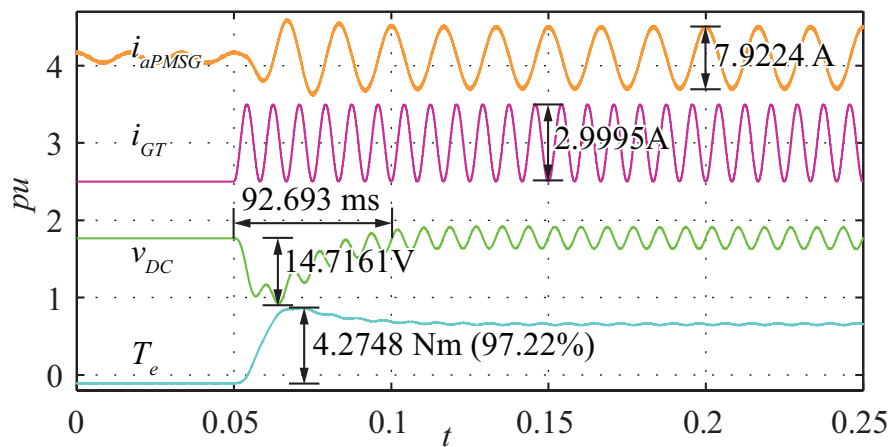

(f) MAF plus lead filter.

Fig. 9: Simulation results: transient responses of the different filtering options for a step of 1.5 A in the grid-side DC-current. As all the filters result in the selected bandwidth of the DC-link voltage control for a fair comparison, the transient responses for all the cases are very similar to each other. The transient duration is in all cases approximately the same $92.62 \mathrm{~ms}$. Torque overshoot is also represented (in parentheses) normalized to the value corresponding to the Butterworth $1^{\text {st }}$ order filter. The torque overshoot for the Butterworth $1^{\text {st }}$ order $\left(100 \%\right.$ normalization value) and $2^{\text {nd }}$ order $(98.29 \%)$ filters is higher because of the presence of torque ripple. The MAF $(97.22 \%)$ results in slightly higher overshoot than the rest of the filters (notch filter 96.55\%, double notch filter 96.56\%, and ARF 96.44\%) due to the presence of the lead filter.

results in slightly higher overshoot than the rest of the filters (notch filter $4.2453 \mathrm{Nm} 96.55 \%$, double notch filter $4.2456 \mathrm{Nm}$ $96.56 \%$, and ARF $4.2401 \mathrm{Nm} 96.44 \%$ ) due to the presence of the lead filter, as explained previously.

\section{EXPERIMENTAL RESULTS}

Fig. 10 shows the experimental set-up. The PMSM is driven by a DC machine supplied by constant DC power supply that emulates the aerodynamic torque. The PMSG is connected to a three-phase, two-level PWM converter controlled by a
dSpace system. The same Simulink blocks used for the simulations were used in the dSpace system. An electronic load is connected to DC-link in order to emulate the connection to the grid through a single phase converter. The DC-link voltage was measured using an inexpensive sensor, which consists of a resistive divider plus an isolation amplifier. In order to obtain a noise-free signal, the electric torque $T_{e}$ is estimated from the reference quadrature current. The $d q$ currents can be approximated to the references, $i_{d} \approx i_{d}^{r e f}$ and $i_{q} \approx i_{q}^{r e f}$, because of the elevated bandwidth. The direct 


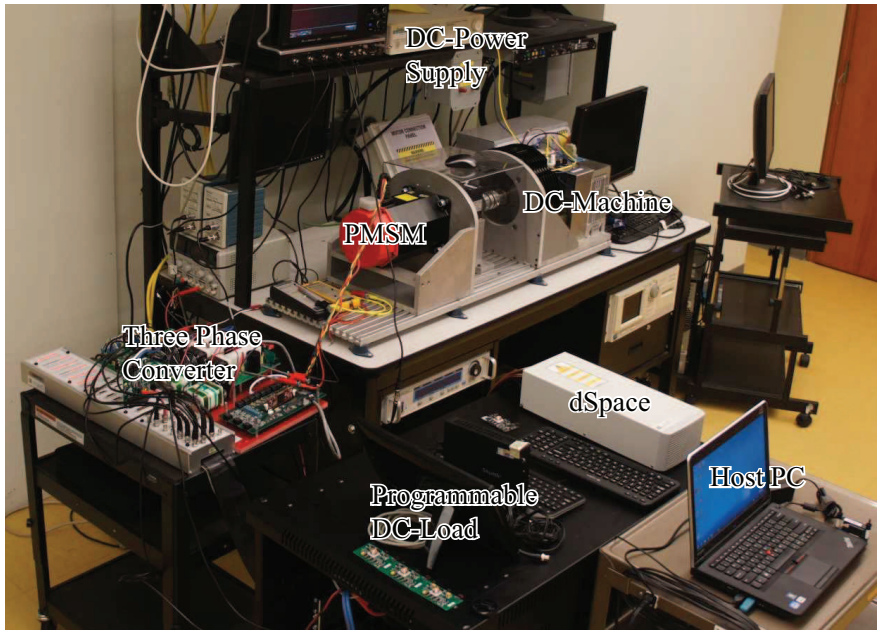

Fig. 10: Experimental set-up for the small WECS.

current is regulated to be zero, as explained in Section II, and the electric torque is approximately $T_{e} \approx 1.5 p_{p} \lambda i_{q}^{r e f}$. The current reference $i_{q}^{r e f}$ is displayed using a DAC connected to the oscilloscope with AC-coupling.

Fig. 11 shows the experimental results of the different filtering options during steady state. The DC-load emulated the grid-tie converter by producing the same DC-current as in the simulations, corresponding to heavily distorted grid voltage. The average value of the grid-side DC-current is $1.5 \mathrm{~A}$. For the comparative analysis, torque ripple will also be represented (in parentheses) normalized to the value corresponding to the Butterworth $1^{\text {st }}$ order filter. It can be seen that Butterworth $1^{\text {st }}$ order and $2^{\text {nd }}$ order filters result in the highest torque ripple with $0.44 \mathrm{Nm}(100 \%)$ and $0.40 \mathrm{Nm}(90.91 \%)$, clearly at double the grid frequency. The notch filter results in $0.38 \mathrm{Nm}$ (86.36\%), and the double notch filter in $0.36 \mathrm{Nm}(81.82 \%)$ : it can be seen that torque ripple has a higher frequency than twice the grid frequency. The MAF has the best results with $0.07 \mathrm{Nm}(15.9 \%)$, practically eliminating the torque ripple. The ARF presents the best second results, with $0.11 \mathrm{Nm}$ (25\%). The results of the ARF and MAF are very close to those predicted in the simulations. This is because their multiple notches cancel the noise due to non-modeled dynamics (non-ideal passive elements and switches, shaft misalignment, asymmetries in the machines, inaccuracies in the dc-load and sensor noise).

Fig. 12 shows the experiment results of the different filtering options for the transients. The tests consists of applying a step of $1.5 \mathrm{~A}$ in the grid-side DC-current. For this case, the grid voltage was sinusoidal. For the comparative analysis, the torque overshoot will also be represented (in parentheses) normalized to the value corresponding to the Butterworth $1^{\text {st }}$ order. The results for all the cases are very similar to each other, as in the previous filter comparison and simulations. This is because all the filters result in the selected bandwidth of the DC-link voltage control for a fair comparison. The transient duration, measured in the DC-voltage, is about 130 ms. The overshoot for the Butterworth $1^{\text {st }}$ order and $2^{\text {nd }}$ order is $3.42 \mathrm{Nm}(100 \%)$, which is the highest value, and which is caused by the presence of torque ripple. The MAF (3.67 $\mathrm{Nm} 107.3 \%$ ) results in slightly higher overshoot than do the

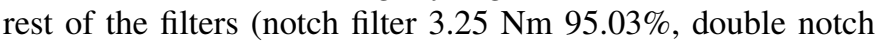

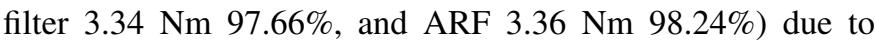
the presence of the lead filter, as explained. The transient is slower and the overshoot is smaller in the experiments than in the simulations because the non-modeled losses of the passive elements and the machine provide additional damping to the system.

Table II shows the summary of results (Simulation and Experimental results, torque normalized to the value corresponding to the Butterworth $1^{\text {st }}$ order) and the computational cost of the different filtering options. It can be seen that the MAF requires an increased number of memory words (126 memory words) and the ARF filter requires a half this value (64 words). However, these amounts of memory are perfectly affordable by current, low-cost DSPs.

\section{CONCLUSION}

This paper show the advantage in terms of stability of using the machine-side inverter to control the DC-link voltage in Small Wind Energy Conversion Systems (WECSs). The Butterworth filter (first and second order), notch filter, antiresonant filter (ARF) and moving average filter (MAF) are considered as means of filtering the DC-link voltage. The Padé approximant is used to calculate the parameters so that the filters result in the same low frequency behavior. In order to obtain flexibility in selecting the bandwidth with the ARF and MAF, an auxiliary lead-lag filter is used. It is shown that the notch filters require few memory words and produce a substantial reduction in the torque ripple. For moderate bandwidth, MAF practically annuls the torque ripple but requires an increased number memory positions, and results in larger overshoot. The ARF requires half the MAF memory positions and produces better results compared to the notch filters. These consideration allow the designer to choose the best option for filtering the DC-link voltage in order to reduce torque ripple.

\section{REFERENCES}

[1] N. Orlando, M. Liserre, R. Mastromauro, and A. Dell'Aquila, "A survey of control issues in pmsg-based small wind-turbine systems," IEEE Trans. Ind. Informatics, vol. 9, no. 3, pp. 1211-1221, Aug 2013.

[2] K.-H. Kim, Y.-C. Jeung, D.-C. Lee, and H.-G. Kim, "Lvrt scheme of pmsg wind power systems based on feedback linearization," IEEE Trans. Power Electron., vol. 27, no. 5, pp. 2376-2384, May 2012.

[3] J. C. Y. Hui, A. Bakhshai, and P. K. Jain, "An energy management scheme with power limit capability and an adaptive maximum power point tracking for small standalone pmsg wind energy systems," IEEE Trans. Power Electron., vol. 31, no. 7, pp. 4861-4875, July 2016.

[4] J. De Kooning, J. Van de Vyver, T. Vandoorn, B. Meersman, and L. Vandevelde, "Joule losses and torque ripple caused by current waveforms in small and medium wind turbines," in EUROCON, 2013 IEEE, July 2013, pp. 889-896.

[5] Y. Xia, K. Ahmed, and B. Williams, "Different torque ripple reduction methods for wind energy conversion systems using diode rectifier and boost converter," in 2011 IEEE Int. Electric Machines Drives Conference (IEMDC), May 2011, pp. 729-734.

[6] I. Jlassi, J. O. Estima, S. K. E. Khil, N. M. Bellaaj, and A. J. M. Cardoso, "Multiple open-circuit faults diagnosis in back-to-back converters of pmsg drives for wind turbine systems," IEEE Trans. Power Electron., vol. 30, no. 5, pp. 2689-2702, May 2015 


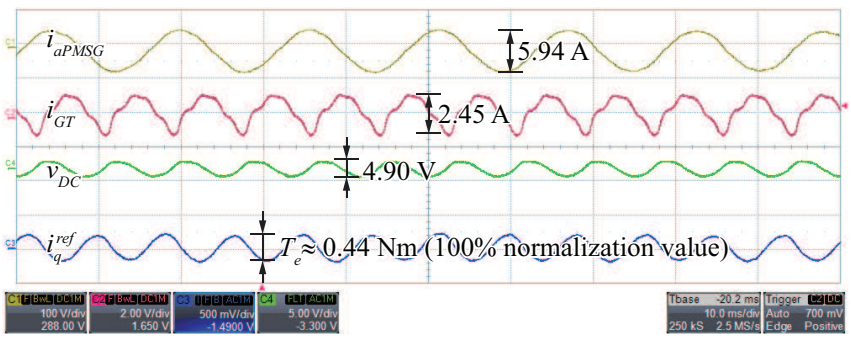

(a) Butterworth $1^{\text {st }}$ order filter.

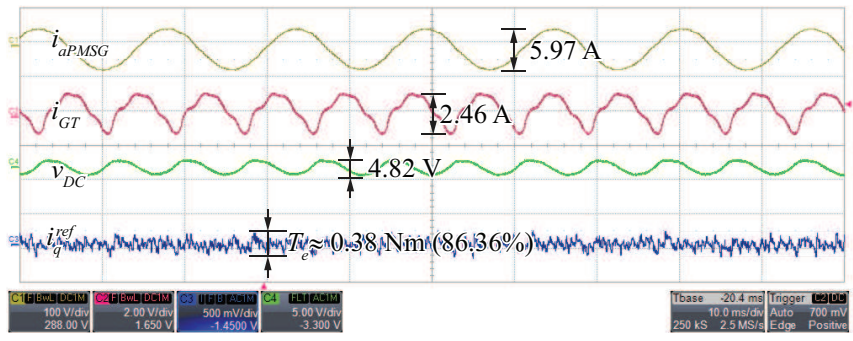

(c) Notch filter.

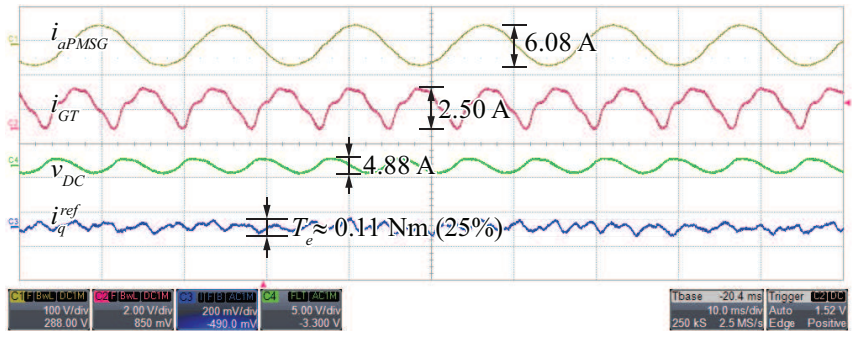

(e) ARF plus lag filter.

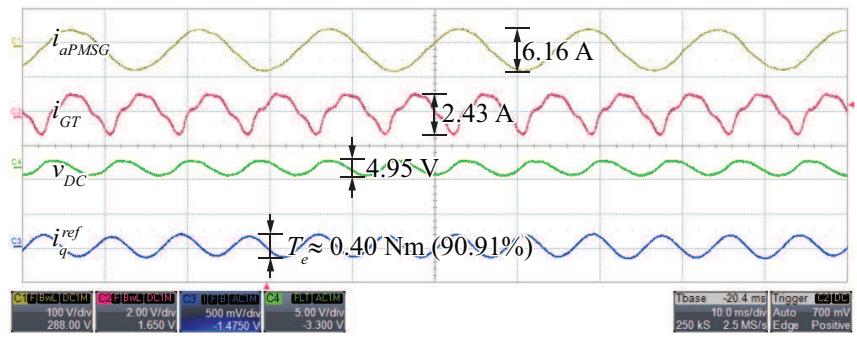

(b) Butterworth $2^{\text {nd }}$ order filter.

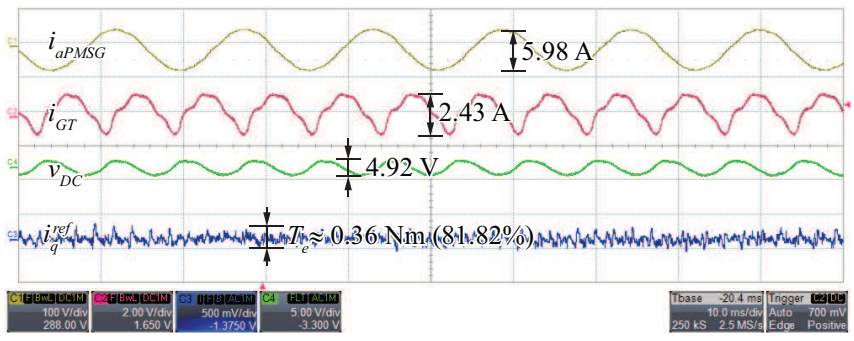

(d) Double Notch filter.

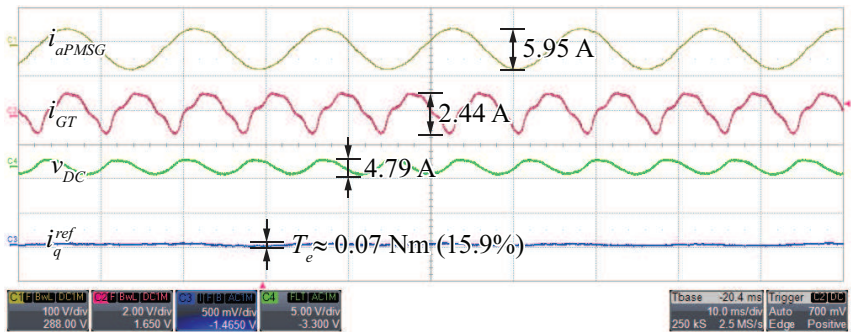

(f) MAF plus lead filter.

Fig. 11: Experimental results: steady state responses of the different filtering options. Torque ripple is also represented (in parentheses) normalized to the value corresponding to the Butterworth $1^{\text {st }}$ order filter. Butterworth $1^{\text {st }}$ order $\left(100 \%\right.$ normalization value) and $2^{\text {nd }}$ order (90.91\%) filters result in the highest torque ripple at double the grid frequency. The notch filter (86.36\%) and the double notch filter (81.82\%) present torque ripple at a higher frequency than twice the grid frequency. The MAF has the best results (15.9\%), practically eliminating the torque ripple. The ARF presents the best second results (25\%). The results of the ARF and MAF are very close to those predicted in the simulations because the multiple notches cancel the noise due to non-modeled dynamics (non-ideal passive elements and switches, shaft misalignment, asymmetries in the machines, inaccuracies in the dc-load and sensor noise).

TABLE II: Summary of results (Simulation and Experimental results, torque normalized to the value corresponding to Butterworth $1^{\text {st }}$ order) and computational cost of the different filtering options. The best result of each column is highlighted in bold type.

\begin{tabular}{|c|c|c|c|c|c|c|c|}
\hline Filter & Ripple Sim. & Overshoot Sim. & Ripple Exp. & Overshoot Exp. & Sums & Mult. & Mem. words \\
\hline Butterworth $1^{\text {st }}$ order & $100 \%$ & $100 \%$ & $100 \%$ & $100 \%$ & 2 & 3 & 1 \\
\hline Butterworth $2^{\text {nd }}$ order & $65.94 \%$ & $98.29 \%$ & $90.91 \%$ & $100 \%$ & 4 & 5 & 2 \\
\hline Notch filter & $34.32 \%$ & $96.55 \%$ & $86.36 \%$ & $95.03 \%$ & 4 & 5 & 2 \\
\hline Double notch filter & $24.98 \%$ & $96.56 \%$ & $81.82 \%$ & $97.66 \%$ & 8 & 10 & 4 \\
\hline ARF + lag filter & $30.47 \%$ & $96.44 \%$ & $25 \%$ & $98.24 \%$ & $2+2$ & $2+3$ & $63+1$ \\
\hline MAF + lead filter & $22.68 \%$ & $97.22 \%$ & $15.9 \%$ & $107.3 \%$ & $1+2$ & $2+3$ & $125+1$ \\
\hline
\end{tabular}

[7] V. Yaramasu and B. Wu, "Predictive control of a three-level boost converter and an npc inverter for high-power pmsg-based medium voltage wind energy conversion systems," IEEE Trans. Power Electron., vol. 29, no. 10, pp. 5308-5322, Oct 2014.

[8] S. Zhang, K.-J. Tseng, D. Vilathgamuwa, T. D. Nguyen, and X.-Y. Wang, "Design of a robust grid interface system for pmsg-based wind turbine generators," IEEE Trans. Ind. Electron., vol. 58, no. 1, pp. 316-328, Jan 2011.

[9] A. Hansen and G. Michalke, "Multi-pole permanent magnet synchronous generator wind turbines' grid support capability in uninterrupted operation during grid faults," Renewable Power Generation, IET, vol. 3, no. 3, pp. 333-348, Sept 2009.

[10] C. Wei, Z. Zhang, W. Qiao, and L. Qu, "An adaptive network-based reinforcement learning method for mppt control of pmsg wind energy conversion systems," IEEE Trans. Power Electron., vol. PP, no. 99, pp. $1-1,2016$.

[11] A. D. Hansen and G. Michalke, "Modelling and control of variable-speed multi-pole permanent magnet synchronous generator wind turbine," Wind Energy, vol. 11, no. 5, pp. 537-554, 2008.

[12] M. Poeller and M. Achilles, "Aggregated wind park models for analyzing power system dynamics," in Fourth Int. workshop on large-scale integration of wind power and transmission networks, October 2003.

[13] A. Hansen, F. Iov, P. Sørensen, N. Cutululis, C. Jauch, F. Blaabjerg, and W. E. D. Risø National Lab., DTU, Dynamic Wind Turbine Models in Power System Simulation Tool DIgSILENT., ser. Contract ENS-1363/040008; ENS-33030-0003; ENS-1363/01-0013. Riso National Laboratory, 


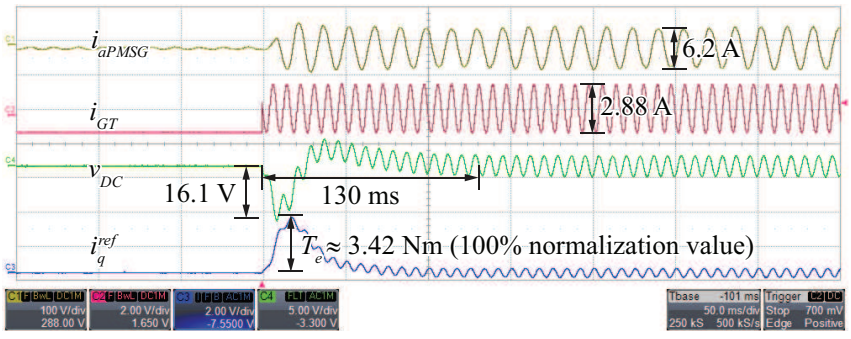

(a) Butterworth $1^{\text {st }}$ order filter.

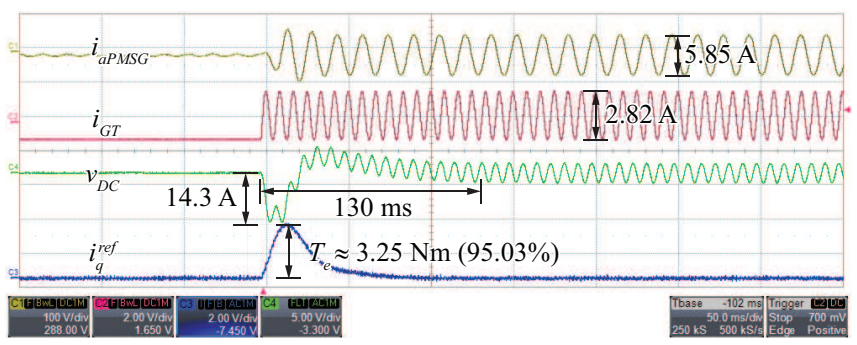

(c) Notch filter.

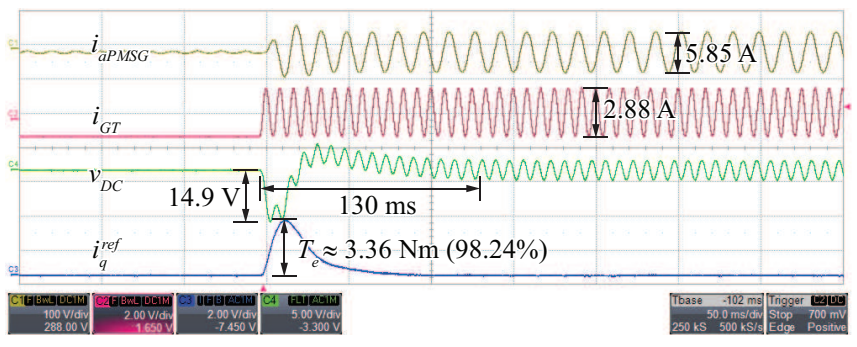

(e) ARF plus lag filter.

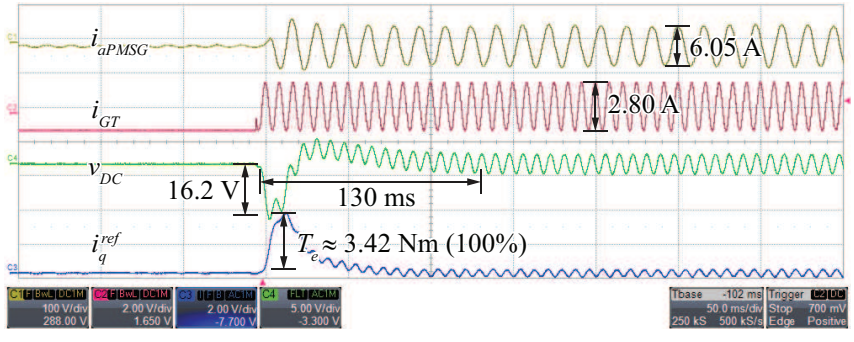

(b) Butterworth $2^{\text {nd }}$ order filter.

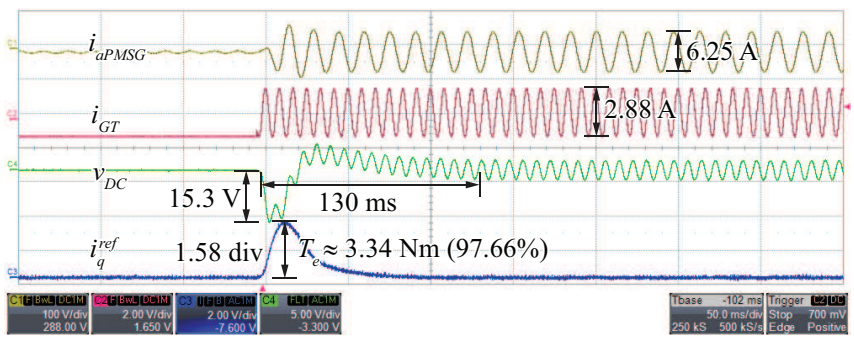

(d) Double Notch filter.

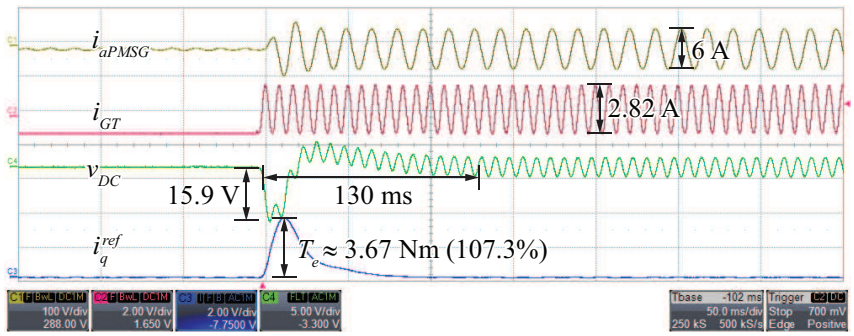

(f) MAF plus lead filter.

Fig. 12: Experimental results: transient response of the different filtering options for a step of 1.5 A in the grid-side DC-current. As all the filters result in the selected bandwidth of the DC-link voltage control for a fair comparison, the transient responses in the experiments for all the cases are very similar to each other. The transient duration, measured in the DC-voltage, is about 130 ms. Torque overshoot is also represented (in parentheses) normalized to the value corresponding to the Butterworth $1^{\text {st }}$ order filter. The torque overshoot for the Butterworth $1^{\text {st }}$ order $\left(100 \%\right.$ normalization value) and $2^{\text {nd }}$ order $(100 \%)$ is the highest value, and is caused by the presence of torque ripple. The MAF (107.3\%) results in slightly higher overshoot than do the rest of the filters (notch filter $95.03 \%$, double notch filter $97.66 \%$, and ARF 98.24\%) due to the presence of the lead filter. The transient is slower and the overshoot is smaller in the experiments than in the simulations because the non-modeled losses of the passive elements and the machine provide additional damping to the system.

Roskilde, 2007.

[14] S. Smith, The Scientist and Engineer's Guide to Digital Signal Processing. California Technical Pub., 1997.

[15] R. Teodorescu, M. Liserre, and P. Rodríguez, Grid Converters for Photovoltaic and Wind Power Systems, ser. Wiley - IEEE. Wiley, 2011.

[16] W. Leonhard, Control of Electrical Drives, ser. Engineering library. Springer Berlin Heidelberg, 2001.

[17] M. Bojrup, "Advanced control of active filters in a battery charger application," Ph.D. dissertation, Lund Institute of Technology (LTH), Sweden, 1999.

[18] F. Freijedo, A. Yepes, O. Lopez, A. Vidal, and J. Doval-Gandoy, “Threephase plls with fast postfault retracking and steady-state rejection of voltage unbalance and harmonics by means of lead compensation," IEEE Trans. Power Electron., vol. 26, no. 1, pp. 85-97, Jan 2011.

[19] R. Pena-Alzola, M. Liserre, F. Blaabjerg, M. Ordonez, and T. Kerekes, "A self-commissioning notch filter for active damping in a three-phase lcl -filter-based grid-tie converter," IEEE Trans. Power Electron., vol. 29, no. 12, pp. 6754-6761, Dec 2014.

[20] S. Vukosavic, Digital Control of Electrical Drives, ser. Power Electronics and Power Systems. Springer US, 2007.

[21] J. Wang, J. Liang, F. Gao, L. Zhang, and Z. Wang, "A method to improve the dynamic performance of moving average filter-based pll," IEEE Trans. Power Electron., vol. 30, no. 10, pp. 5978-5990, Oct 2015.

[22] S. Golestan, M. Ramezani, J. Guerrero, F. Freijedo, and M. Monfared,
"Moving average filter based phase-locked loops: Performance analysis and design guidelines," IEEE Trans. Power Electron., vol. 29, no. 6, pp. 2750-2763, June 2014.

[23] K. Fujii and R. De Doncker, "A novel dc-link voltage control of pwmswitched cascade cell multi-level inverter applied to statcom," in Fortieth IAS Annu. Meeting. Conf. Rec. of the 2005 Ind. Applicat. Conf., 2005., vol. 2, Oct 2005, pp. 961-967 Vol. 2.

[24] J. Yutaka Ota, Y. Shibano, and H. Akagi, "A phase-shifted pwm dstatcom using a modular multilevel cascade converter (ssbc) part ii: Zerovoltage-ride-through capability," IEEE Trans. Ind. Applicat., vol. 51, no. 1, pp. 289-296, Jan 2015.

[25] P. Ksiazek and M. Ordonez, "Swinging bus technique for ripple current elimination in fuel cell power conversion," IEEE Trans. Power Electron., vol. 29, no. 1, pp. 170-178, Jan 2014.

[26] A. D. Hansen, M. Altin, I. D. Margaris, F. Iov, and G. C. Tarnowski, "Analysis of the short-term overproduction capability of variable speed wind turbines," Renewable Energy, vol. 68, pp. 326 - 336, 2014.

[27] J. Steinke, "Use of an lc filter to achieve a motor-friendly performance of the pwm voltage source inverter," IEEE Trans. on Energy Conversion, vol. 14, no. 3, pp. 649-654, Sep 1999.

[28] S. w. Liu and G. q. Bao, "A novel lvrt of permanent magnet direct-driven wind turbine," in Power and Energy Engineering Conference (APPEEC), 2011 Asia-Pacific, March 2011, pp. 1-4.

[29] S. Dong, Y. Wang, and H. Li, "Coordinated control for active and reac- 
tive power of pmsg-based wind turbine to enhance the lvrt capability," in Electrical Machines and Systems (ICEMS), 2012 15th International Conference on, Oct 2012, pp. 1-4.

[30] H. Geng, D. Xu, B. Wu, and G. Yang, "Active damping for torsional vibrations in pmsg based wecs," in Applied Power Electronics Conference and Exposition (APEC), 2010 Twenty-Fifth Annual IEEE, Feb 2010, pp. 2126-2131.

[31] H. Geng, G. Yang, D. Xu, and B. Wu, "Unified power control for pmsg-based wecs operating under different grid conditions," IEEE Transactions on Energy Conversion, vol. 26, no. 3, pp. 822-830, Sept 2011.

[32] J. Suul, M. Molinas, L. Norum, and T. Undeland, "Tuning of control loops for grid connected voltage source converters," in IEEE 2nd Int. Power and Energy Conf. 2008. PECon 2008., Dec 2008, pp. 797-802.

[33] V. Blasko and V. Kaura, "A new mathematical model and control of a three-phase ac-dc voltage source converter," IEEE Trans. Power Electron., vol. 12, no. 1, pp. 116-123, Jan 1997.

[34] J. Umland and M. Safiuddin, "Magnitude and symmetric optimum criterion for the design of linear control systems: what is it and how does it compare with the others?" IEEE Trans. Ind. Applicat., vol. 26, no. 3, pp. 489-497, May 1990.

[35] A. Yazdani and R. Iravani, "An accurate model for the dc-side voltage control of the neutral point diode clamped converter," IEEE Trans. Power Delivery, vol. 21, no. 1, pp. 185-193, Jan 2006.

[36] K. Astrom and B. Wittenmark, Adaptive Control, ser. Addison-Wesley series in electrical engineering : control engineering. Addison-Wesley, 1995.

[37] C. Klumpner, M. Liserre, and F. Blaabjerg, "Improved control of an active-front-end adjustable speed drive with a small de-link capacitor under real grid conditions," in 2004 IEEE 35th Ann. Power Electron. Specialists Conf., 2004. PESC 04., vol. 2, June 2004, pp. 1156-1162 Vol.2.

[38] R. Teodorescu, F. Blaabjerg, U. Borup, and M. Liserre, "A new control structure for grid-connected $\mathrm{lcl} \mathrm{pv}$ inverters with zero steady-state error and selective harmonic compensation," in Nineteenth Annu. IEEE App. Power Electron. Conf. and Expo., 2004. APEC '04., vol. 1, 2004, pp. 580-586 Vol.1.

[39] W. Yang, W. Cao, T. Chung, and J. Morris, Applied Numerical Methods Using MATLAB. Wiley, 2005.

[40] E.-K. Press, G. Franklin, J. Powell, and M. Workman, Digital Control of Dynamic Systems. Ellis-Kagle Press, 1998.

[41] J. Svensson, M. Bongiorno, and A. Sannino, "Practical implementation of delayed signal cancellation method for phase-sequence separation," IEEE Trans. on Power Delivery, vol. 22, no. 1, pp. 18-26, Jan 2007.

[42] L. Wang, Q. Jiang, L. Hong, C. Zhang, and Y. Wei, "A novel phaselocked loop based on frequency detector and initial phase angle detector," IEEE Trans. Power Electron., vol. 28, no. 10, pp. 4538-4549, Oct 2013.

[43] R. Ottersten, "On control of back-to-back converters and sensorless induction machine drivers," Ph.D. dissertation, Chalmers University of Technology, Goteborg, Sweden, 2003.

[44] L. Harnefors and H.-P. Nee, "A general algorithm for speed and position estimation of ac motors," IEEE Trans. Ind. Electron., vol. 47, no. 1, pp. 77-83, Feb 2000.

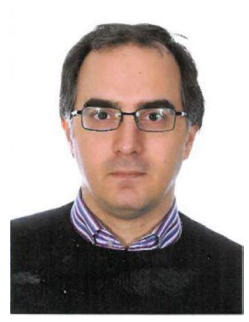

Rafael Peña Alzola received the combined licentiate and M.Sc. degree in industrial engineering from the University of the Basque Country, Bilbao, Spain, in 2001, and the Ph.D. degree from the National University for Distance Learning, UNED, Madrid, Spain, in 2011. He has worked as an electrical and control engineer for several companies in Spain. From September 2012 to July 2013, he has been Guest Postdoc in the Department of Energy Technology at Aalborg University, Aalborg, Denmark.

Since August 2014 he is Postdoc Research Fellow at the Department of Electrical and Computer Engineering at The University of British Columbia (UBC) in Vancouver, Canada. His research interests are energy storage, LCL-filters, solid-state transformers and innovative control techniques for power converters.

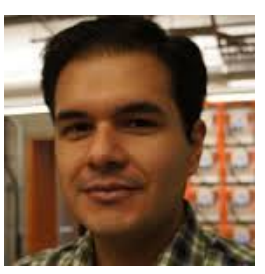

David Campos-Gaona (M'12) received the B.E. degree in Electronic Engineering and the M.Sc. and $\mathrm{Ph} . \mathrm{D}$. degrees in Electrical Engineering from Instituto Tecnolgico de Morelia, Morelia, Mexico, in 2004,2007 , and 2012 , respectively.

From 2014 to 2016 he was a Postdoctoral Research Fellow with the Department of Electrical and Computer Engineering, University of British Columbia. (UBC), Canada. Since august 2016 he is a Research Associate with the University of Strathclyde, United Kingdom. His areas of interest include wind farm power integration, HVDC transmission systems, and digital control of power-electronic-based devices.

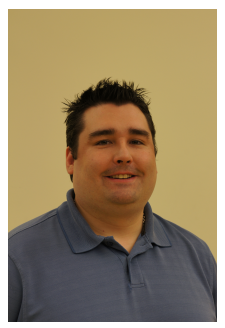

Peter F. Ksiazek (S07-M14) was born in Lethbridge, AB, Canada. He received the EET diploma from the Northern Alberta Institute of Technology in 2008, the B.Eng. degree from the University of Victoria in 2012, and in 2014 the M.A.Sc degree from the University of British Columbia, Vancouver, BC, Canada. During his master's he studied power electronics and renewable energy extraction techniques and was awarded the prestigious NSERC Alexander Graham Bell Canada Graduate Scholarship in 2013.

In addition, he was awarded scholarships from the Kaiser Foundation for Higher Education in 2012 and 2013. He is currently with Alpha Technologies Ltd. (Burnaby, BC, Canada) where he assists with the development of high efficiency and high reliability power converters for the telecommunications industry. Mr. Ksiazek's research interests include power electronic controls, resonant topologies, and renewable energy extraction techniques.

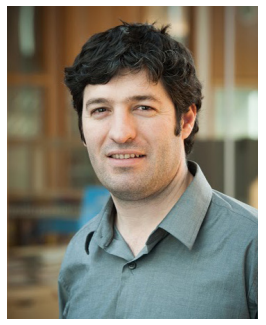

Martin Ordonez (S02M09) was born in Neuquen, Argentina. He received the Ing. degree in electronics engineering from the National Technological University, Cordoba, Argentina, in 2003, and the M.Eng. and Ph.D. degrees in electrical engineering from the Memorial University of Newfoundland (MUN), St. Johns, NL, Canada, in 2006 and 2009, respectively. He is currently the Canada Research Chair in Power Converters for Renewable Energy Systems and Assistant Professor with the Department of Electrical and Computer Engineering, University of British Columbia, Vancouver, BC, Canada. He was an adjunct Professor with Simon Fraser University, Burnaby, BC, Canada, and MUN. His industrial experience in power conversion includes research and development at Xantrex Technology Inc./Elgar Electronics Corp. (now AMETEK Programmable Power in San Diego, California), Deep-Ing Electronica de Potencia (Rosario, Argentina), and TRV Dispositivos (Cordoba, Argentina). With the support of industrial funds and the Natural Sciences and Engineering Research Council, he has contributed to more than 90 publications and R\&D reports.

Dr. Ordonez is an Associate Editor of the IEEE TRANSACTIONS ON POWER ELECTRONICS, serves on several IEEE committees, and reviews widely for IEEE/IET journals and international conferences. He was awarded the David Dunsiger Award for Excellence in the Faculty of Engineering and Applied Science (2009) and the Chancellors Graduate Award/Birks Graduate Medal (2006), and became a Fellow of the School of Graduate Studies, MUN. 